\title{
Human carcinoma-associated mesenchymal stem cells promote ovarian cancer chemotherapy resistance via a BMP4/HH signaling loop
}

\author{
Lan G. Coffman ${ }^{1, *}$, Yun-Jung Choi ${ }^{1, *}$, Karen McLean², Benjamin L. Allen ${ }^{3}$, Marina \\ Pasca di Magliano ${ }^{3,4}$ and Ronald J. Buckanovich ${ }^{1,2}$ \\ ${ }^{1}$ Division of Hematology Oncology, Department of Internal Medicine, University of Michigan Medical Center, Ann Arbor, \\ Michigan, USA \\ 2 Division of Gynecologic Oncology, Department of Obstetrics and Gynecology, University of Michigan Medical Center, Ann \\ Arbor, Michigan, USA \\ ${ }^{3}$ Department of Cell and Developmental Biology, University of Michigan Medical Center, Ann Arbor, Michigan, USA \\ ${ }^{4}$ Department of Surgery, University of Michigan Medical Center, Ann Arbor, Michigan, USA \\ * These authors have contributed equally to this work and should be considered as co-first authors \\ Correspondence to: Lan G. Coffman, email: coffmanl@med.umich.edu \\ Keywords: ovarian cancer, mesenchymal stem cell, tumor microenvironment, BMP4, Hedgehog \\ Received: September 14,2015 Accepted: January 01,2016 Published: January 09, 2016
}

\section{ABSTRACT}

The tumor microenvironment is critical to cancer growth and therapy resistance. We previously characterized human ovarian carcinoma-associated mesenchymal stem cells (CA-MSCs). CA-MSCs are multi-potent cells that can differentiate into tumor microenvironment components including fibroblasts, myofibroblasts and adipocytes. We previously reported CA-MSCs, compared to normal MSCs, express high levels of BMP proteins and promote tumor growth by increasing numbers of cancer stemlike cells (CSCs). We demonstrate here that ovarian tumor cell-secreted Hedgehog (HH) induces CA-MSC BMP4 expression. CA-MSC-derived BMP4 reciprocally increases ovarian tumor cell $\mathrm{HH}$ expression indicating a positive feedback loop. Interruption of this loop with a HH pathway inhibitor or BMP4 blocking antibody decreases CA-MSCderived BMP4 and tumor-derived HH preventing enrichment of CSCs and reversing chemotherapy resistance. The impact of $\mathrm{HH}$ inhibition was only seen in CA-MSCcontaining tumors, indicating the importance of a humanized stroma. These results are reciprocal to findings in pancreatic and bladder cancer, suggesting $\mathrm{HH}$ signaling effects are tumor tissue specific warranting careful investigation in each tumor type. Collectively, we define a critical positive feedback loop between CA-MSC-derived BMP4 and ovarian tumor cell-secreted $\mathrm{HH}$ and present evidence for the further investigation of $\mathrm{HH}$ as a clinical target in ovarian cancer.

\section{INTRODUCTION}

Ovarian cancer is the most deadly US gynecologic malignancy, killing over 14,000 women yearly [1]. Most ovarian cancer cases are diagnosed as late stage disease with diffuse peritoneal metastasis indicating an ovarian cancer tropism for the intra-abdominal microenvironment. Despite initial chemotherapeutic response, most ovarian cancer patients will develop recurrent disease. Inevitably, recurrent disease will become resistant to standard platinum-based chemotherapy ultimately leading to patient death. The tumor microenvironment is critical for the growth, spread and survival of cancer cells with emerging data describing the importance of stromal components such as adipocytes and cancer associated fibroblasts in ovarian cancer [2-5].

Mesenchymal stem cells (MSCs) are an important component of the tumor microenvironment $[6,7]$. MSCs were first characterized from bone marrow, adipose and embryonic tissues and are well-documented to travel to tumor sites [8-10]. MSCs have now been reported in a variety of other tissues including ovary, brain, spleen, liver, kidney, lung, muscle, thymus, pancreas, eyelid, and the peri-vasculature [11-13], suggesting MSCs may be present in many tissues throughout tumor initiation and growth. 
Recently our lab isolated primary human ovarian carcinoma-associated MSCs (CA-MSCs) [14]. CAMSCs are distinct from cancer associated fibroblasts; CA-MSCs meet all the established criteria for MSCs [15] with appropriate surface marker expression and multipotent differentiation potential. As a multipotent stem cell population, CA-MSCs (unlike cancer associated fibroblasts) will passage for many months in culture. CA-MSCs have a normal genome and do not form tumors [16]. However, CA-MSCs are strongly pro-tumorigenic, increasing both tumor growth and "stemness" [14]. Importantly, as CA-MSCs are multipotent cells capable of differentiating into several critical components of the tumor stroma including fibroblasts, osteocytes and adipocytes [15], therapeutic targeting of CA-MSCs could impact multiple components of the tumor microenvironment and thereby have a powerful anti-tumor effect.

CA-MSCs have a unique expression profile compared to normal adipose, bone marrow or ovary derived MSCs characterized by increased $B M P$ expression (particularly $B M P 2$ and $B M P 4$ ) $[14,16]$. The factors leading to the unique expression profile of CA-MSCs are unknown; however our previous work suggests that tumorsecreted factors contribute to the CA-MSC expression profile.

One potential tumor derived CA-MSC regulating factor is Hedgehog $(\mathrm{HH})$. HH signaling, which is critical during development and in maintenance of the adult stem cell pool, is a key regulator of BMP expression [17]. $\mathrm{HH}$ signaling also has emerging roles in tumor/stromal signaling [18]. In ovarian cancer, increased HH signaling is correlated with poor outcomes [19] and HH signaling is increased in ovarian cancer at the time of disease recurrence [20]. HH appears to be particularly important in the tumor microenvironment as $\mathrm{HH}$ signaling in ovarian tumor stroma is associated with enhanced chemoresistance and decreased survival $[3,19,21]$. In contrast, $\mathrm{HH}$ signaling appears to restrict tumor progression in bladder cancer and $\mathrm{HH}$ inhibition produced negative clinical results in pancreatic cancer. These contrasting results highlight the complexity of the $\mathrm{HH}$ pathway and may indicate tissue specific effects of HH signaling which would be unsurprising given the divergent effects of $\mathrm{HH}$ in spatiotemporal gradients during development [22, 23].

We investigated a possible role for $\mathrm{HH}$ signaling in CA-MSCs. We demonstrate that tumor-derived HH drives CA-MSC BMP4 production. CA-MSC-derived BMP4 reciprocally increases $\mathrm{HH}$ production in ovarian cancer cells thus creating a positive feedback loop between the tumor and CA-MSCs. This feedback loop promoted chemotherapy resistance both in vitro and in vivo. In vivo pharmacologic $\mathrm{HH}$ inhibition abrogated the protumorigenic effects of CA-MSCs preventing increases in cancer stem cell-like cell (CSC) percentage and reversed chemotherapy resistance indicating that $\mathrm{HH}$ signaling is critical for the tumor growth promoting function of CAMSCs.

\section{RESULTS}

\section{Hedgehog signaling is active in the stroma of normal ovary and ovarian cancer}

To explore the role of $\mathrm{HH}$ signaling in the ovarian cancer microenvironment we first confirmed $\mathrm{HH}$ signaling in normal ovarian tissue and ovarian tumors. To confirm HH activity in normal ovaries and ovarian tumors we used a Gli1 ${ }^{\text {lacz }}$ reporter mouse [24, 25]. Gli1 is both a downstream component of $\mathrm{HH}$ signaling and a transcriptional target, thus its expression indicates pathway activation [26]. We observed strong Beta-Galactosidase $(\beta-G a l)$ activity throughout the normal murine ovarian stroma (Figure 1Ai). $\beta$-Gal expression was not observed in the ovarian surface epithelium, in developing follicles, or in the epithelial lining of the oviduct (the murine equivalent of the fallopian tube). $\beta$-Gal expression was detected in the peri-vasculature; a reported location for tissue associated MSCs [12].

To determine if $\mathrm{HH}$ signaling is active in ovarian tumor stroma, we transplanted ID8 mouse ovarian tumor cells into the flank of Gli $1^{\text {lacZ }}$ mice. $\beta$-Gal as an indicator of HH signaling was clearly noted within the tumor stroma with significantly less $\beta$-Gal in adjacent non-tumor stroma (Figure 1Aii, iii). To confirm HH signaling in human ovarian cancer, qRT-PCR of cDNA generated from primary human ovarian tumor samples were analyzed. Consistent with previous results [27], GLII and GLI3 (HH pathway transcriptional effectors), $\mathrm{PTCH}$ ( $\mathrm{HH}$ signaling repressor and target gene), $S M O$ (HH signaling activator), $\mathrm{IHH}$ and $\mathrm{SHH}$ (HH pathway ligands) were expressed in ovarian tumors, albeit at variable levels (Figure 1B).

\section{Mesenchymal stem cells respond to $\mathrm{HH}$ ligands produced by ovarian cancer cells}

Given the largely stromal localization of $\mathrm{HH}$ pathway activation, we next explored the ability of MSCs to respond to $\mathrm{HH}$ signaling. We tested the ability of both normal ovary derived MSCs (Ov-MSCs) and, given the predilection of ovarian cancer for omental adipose, normal adipose derived MSCs (A-MSCs) to respond to $\mathrm{HH}$. A-MSCs and Ov-MSCs treated with recombinant Sonic Hedgehog ( $\mathrm{SHH}$ ) demonstrated increased expression of downstream targets of the canonical HH pathway indicating both MSC groups respond to $\mathrm{HH}$ signaling (Figure 1C, 1D). CA-MSCs also demonstrated clear response to $\mathrm{HH}$ treatment with induction of $G L I 1, S M O$, PTCHI and GASl (Figure 1D).

To determine if cancer cells are a source of $\mathrm{HH}$ 
ligands, we treated CA-MSCs with conditioned media from multiple ovarian cancer cell lines or primary human ovarian cancer cell cultures. The induction of $\mathrm{HH}$ responsive genes was analyzed via qRT-PCR. Tumor conditioned media (TCM) lead to a similar pattern of $\mathrm{HH}$ target gene induction as seen with recombinant SHH (Figure 1E). This suggests that ovarian cancer cells produce $\mathrm{HH}$ ligands that can activate $\mathrm{HH}$ signaling pathways in MSCs.

Ai)

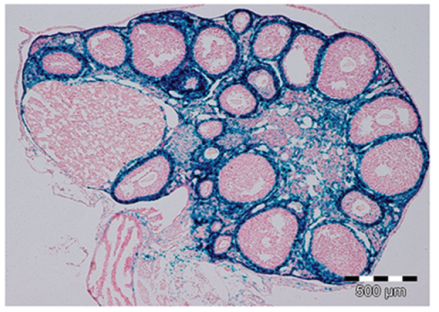

ii)

iii)

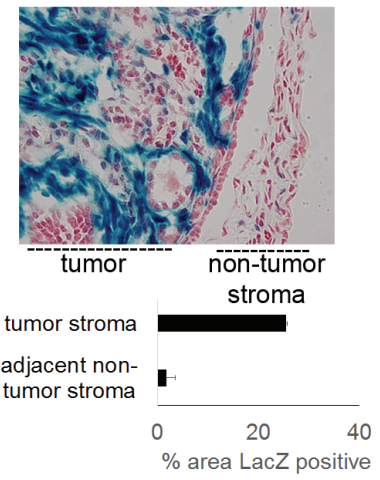

C)

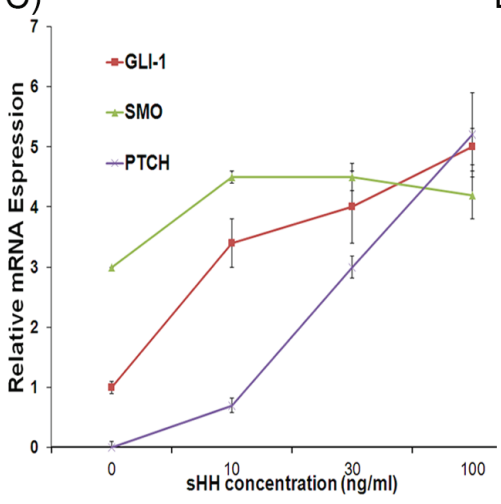

B) 1000
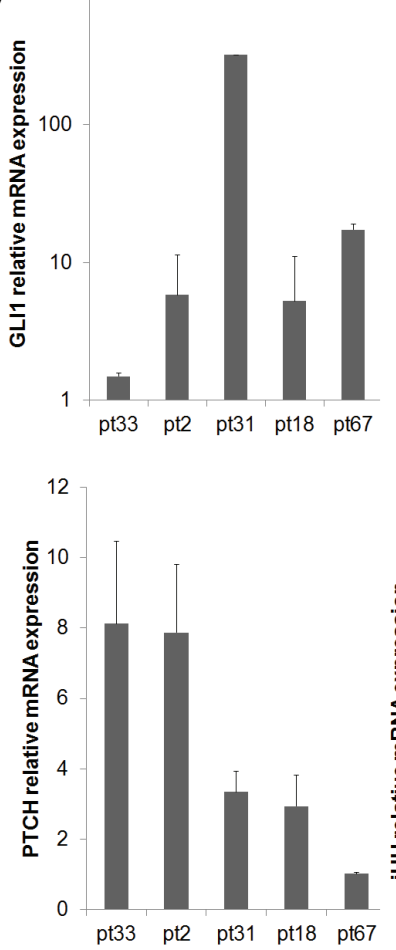

Tumor-derived $\mathrm{HH}$ differentially induces the expression of BMP4 in CA-MSCs

Given (i) the responsiveness of MSCs to $\mathrm{HH}$ signaling, (ii) the role of $\mathrm{HH}$ in regulating $B M P$ expression [17], and (iii) the differential expression of $B M P \mathrm{~s}$ in CA-MSCs compared to normal controls, we assessed if $\mathrm{HH}$ activation could be the etiology of increased BMP
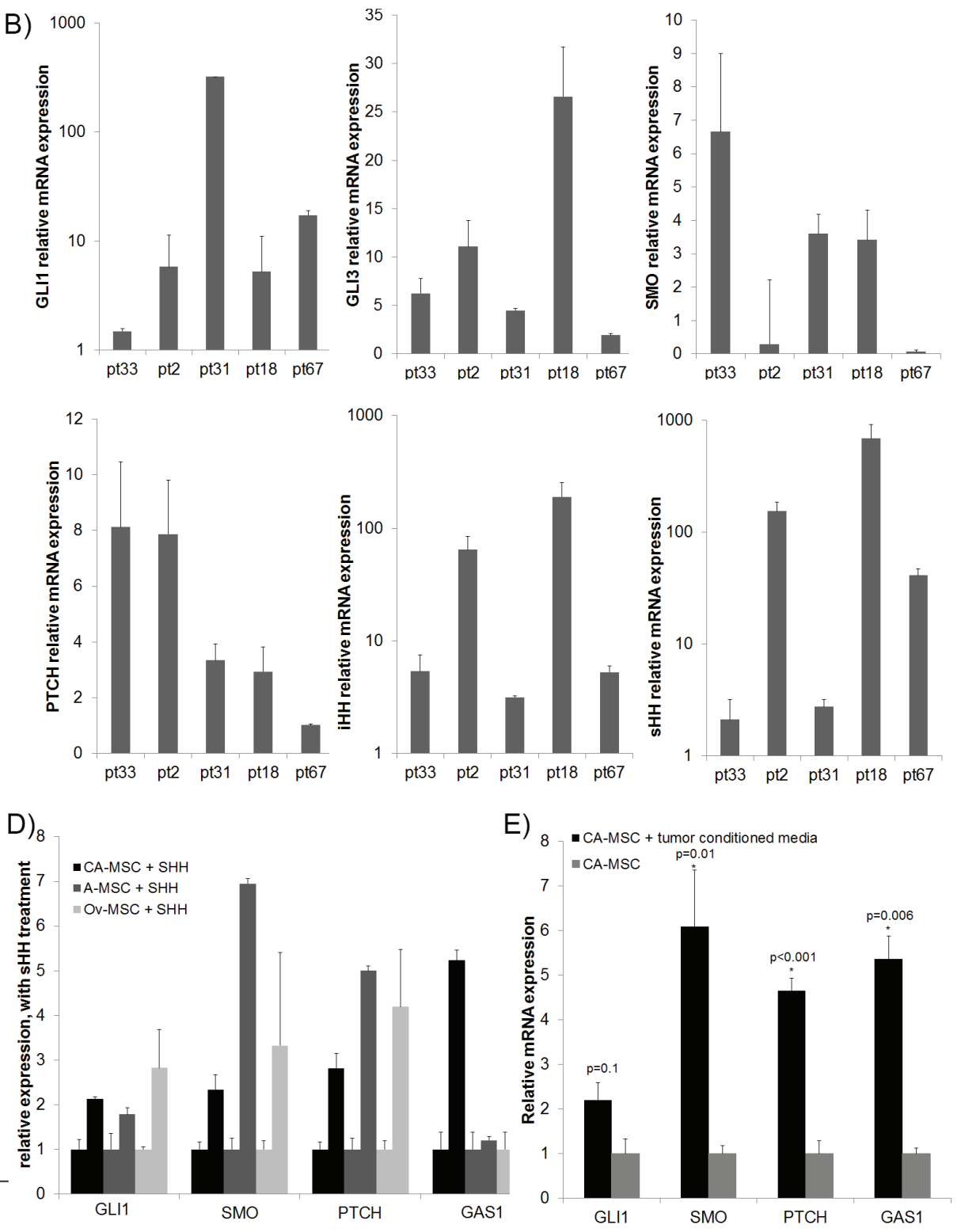

Figure 1: HH signaling is active in the normal ovary, ovarian tumor stroma and in MSCs. A. Gli1-LacZ reporter mice demonstrate Gli1 expression (blue) in i) normal ovary stroma, and ii) ID8 ovarian tumor stroma with iii) quantification of Gli1-LacZ positive area in tumor stroma vs non-tumor stroma demonstrating significantly higher levels in tumor stroma (quantification via ImageJ analysis in 3 tumor and non-tumor sections). B. qRT-PCR analysis of GLI1, GLI3, SMO, PTCH, IHH and SHH in primary ovarian tumors confirming HH signaling components are expressed in all tumors tested. C. SHH treatment of normal adipose derived MSCs demonstrate dose dependent activation of the canonical HH signaling pathway (data are normalized to untreated adipose MSC GLI1 value). D. qRT-PCR demonstrating treatment of A-MSCs, normal ovary (Ov-MSCs) and CA-MSCs with recombinant SHH activates HH signaling pathway. E. qRT-PCR demonstrating tumor conditioned media (TCM) likewise activates HH signaling in CA-MSCs. Error bars=standard error of the mean. 
signaling in CA-MSCs. qRT-PCR analysis confirmed greater baseline expression of $B M P 2$ and $B M P 4$ in CAMSCs compared to normal Ov-MSCs and A-MSCs (data not shown and Figure 2A). HH treatment of A-MSCs and Ov-MSCs did not result in a significant (0-2.8 fold) induction of either BMP2 or BMP4 (Supplemental Figure 1 and Figure 2B). However, treatment of CA-MSCs with $\mathrm{HH}$ led to significant induction (5-30 fold) of BMP4 (Figure 2B). BMP2 expression was modestly increased in CA-MSCs (Supplemental Figure 1).

Given the HH-mediated induction of BMP4 in CA-MSCs, we investigated if tumor derived $\mathrm{HH}$ could likewise induce BMP4 expression. CA-MSCs were treated with TCM from three human ovarian cancer cell lines (SKOV3, COV318, CAOV-3). BMP4 expression was increased in response to treatment with all three TCM (Figure 2C). Treatment with IPI-926, a SMO inhibitor, significantly decreased the TCM-mediated induction of
BMP4 transcription (Figure 2C) and BMP4 protein levels (Figure 2D) suggesting activation of BMP4 expression is via tumor cell produced $\mathrm{HH}$ ligands.

\section{A paracrine HH-BMP4 ovarian cancer cell-CA- MSC positive feedback loop}

We previously showed that CA-MSC-derived BMP directly impacts ovarian cancer cells [14]. We therefore hypothesized that CA-MSC-derived BMP4 may alter $H H$ expression in tumor cells though a feedback mechanism. To investigate this possibility, we treated ovarian cancer cells with recombinant BMP4 and analyzed $\mathrm{SHH}$ expression via qRT-PCR. $S H H$ expression was increased in SKOV3 and CAOV-3 cell lines after 48hrs of BMP4 treatment (Figure 3A). This induction was seen at both early (16hr) and later (48hr) time points (data not
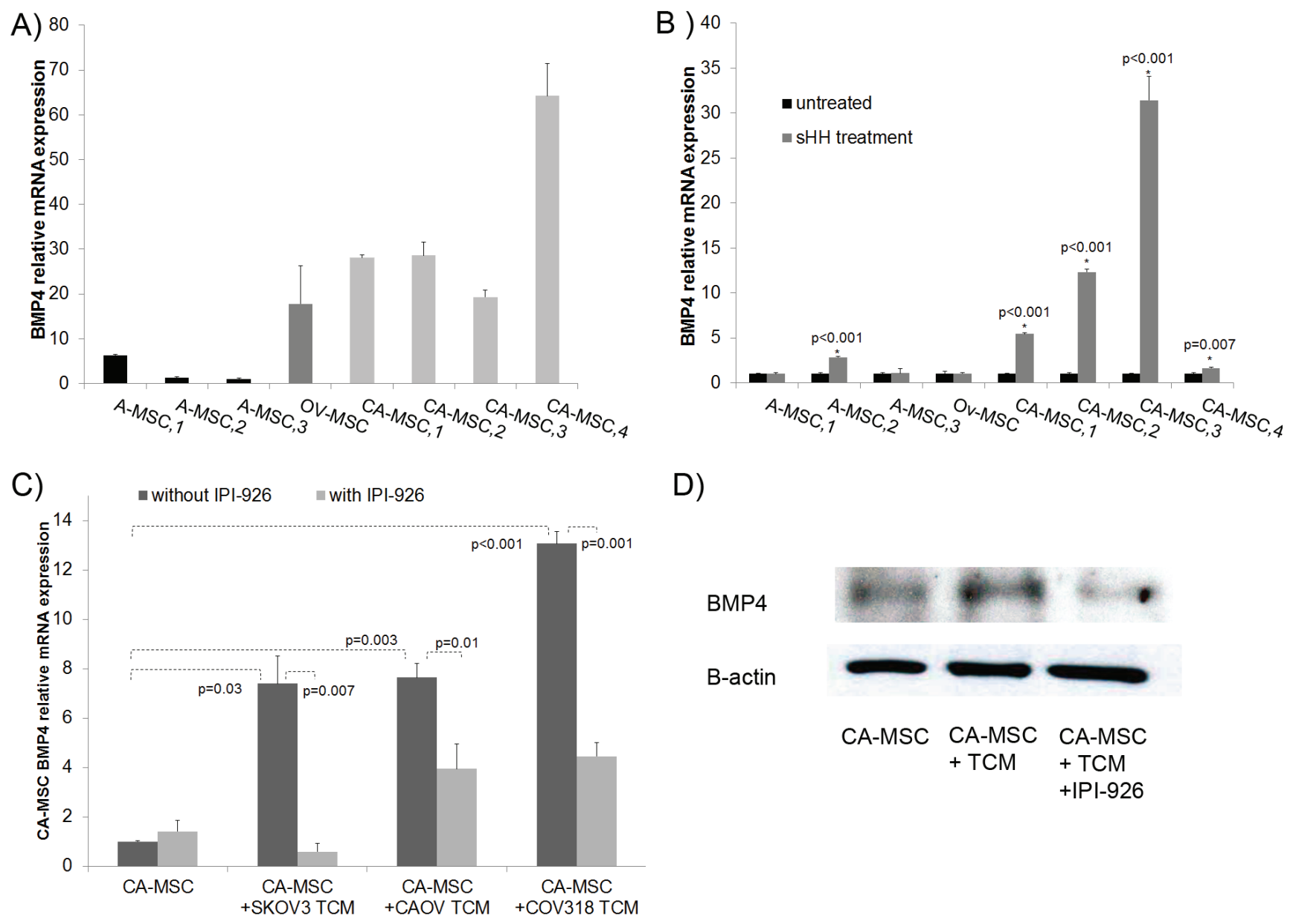

D)

BMP4

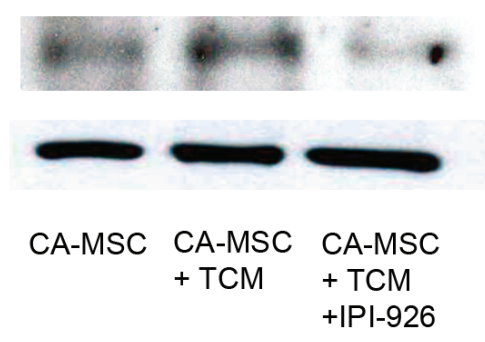

Figure 2: CA-MSCs respond to tumor derived HH with increased BMP4. A. qRT-PCR analysis of BMP4 expression in normal adipose MSCs (A-MSC1,2,3), normal ovary MSCs (Ov-MSC) and patient derived CA-MSCs (CA-MSC 1-4) demonstrating higher baseline BMP4 expression in CA-MSCs, relative expression compared to A-MSC3. B. qRT-PCR analysis of BMP4 expression in A-MSC, Ov-MSC and CA-MSCs without and with SHH demonstrating SHH-mediated BMP4 induction in CA-MSCs (expression is normalized to untreated controls for each pair). C. qRT-PCR analysis of BMP4 expression in CA-MSCs demonstrating that tumor conditioned media (TCM) derived from 3 ovarian cancer cell lines induces BMP4 expression and this induction can be blocked by the HH inhibitor IPI-926, all samples normalized to CA-MSC without IPI-926. D. Western blot of BMP4 protein levels in CA-MSCs \pm TCM with or without IPI-926. Error bars $=$ standard error of the mean. 
shown) indicating that BMP4 treatment is not selecting for a population of cells with higher $\mathrm{SHH}$ expression but inducing a general increase in $\mathrm{SHH}$ expression. In the COV318 ovarian cancer cell line, BMP4 treatment induced $\mathrm{IHH}$ rather than $\mathrm{SHH}$ (Figure 3B). HH induction was verified at the protein level via western blot (Figure
3C). The reciprocal induction of tumor derived $H H$ by BMP4 creates a possible signaling loop with tumor derived $\mathrm{HH}$ and CA-MSC derived BMP4.To investigate the possibility of this positive feedback loop, we next utilized a transwell system for co-culture of CA-MSCs and ovarian tumor cells. The transwell membrane allowed
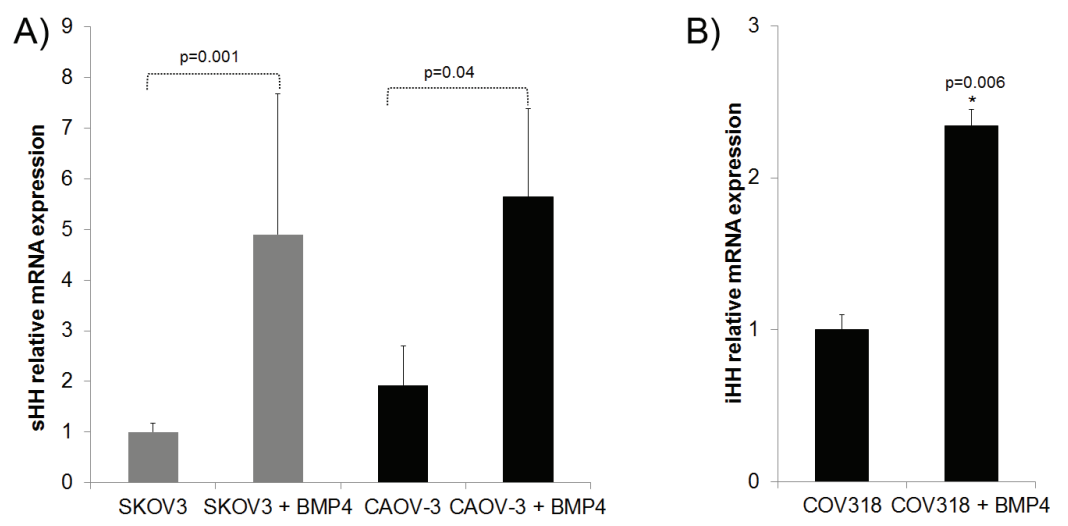

C)

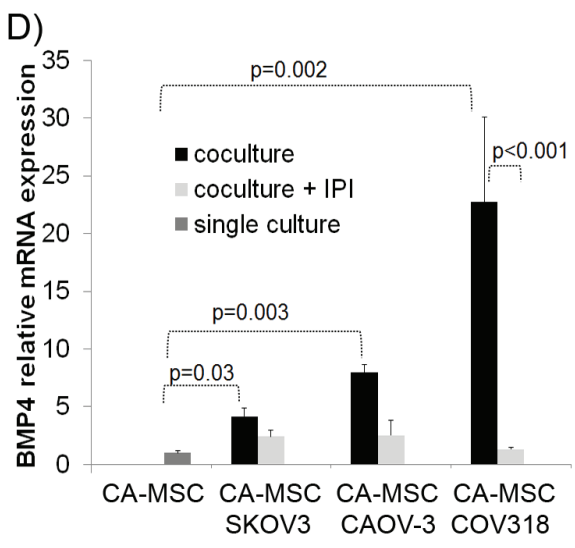

$\mathrm{Ei}_{4.5}$
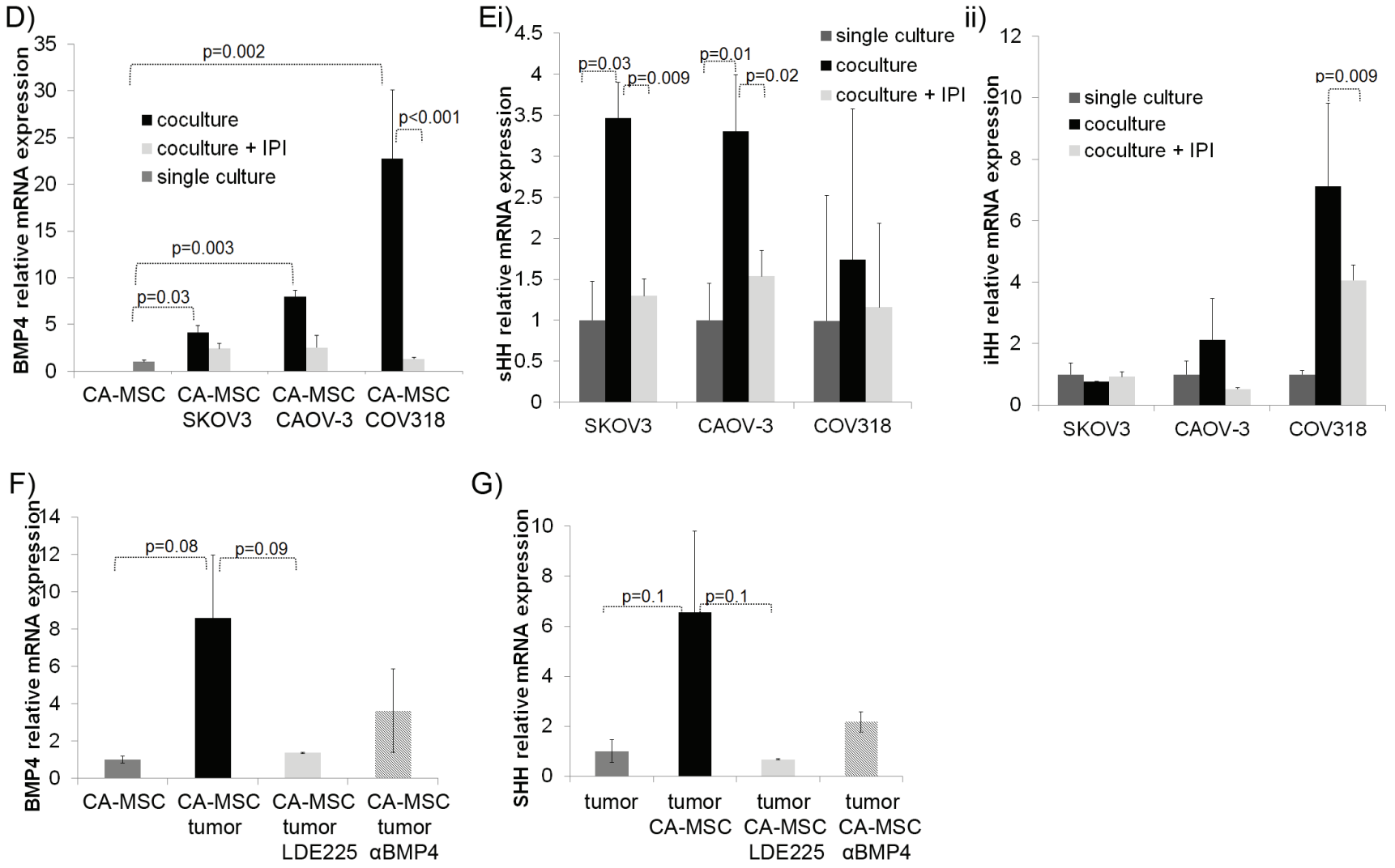

Figure 3: Ovarian tumor cells respond to BMP4 with increased HH forming a positive feedback loop interrupted by HH inhibition. A. qRT-PCR analysis of ovarian cancer lines SKOV3 and CAOV-3 treated with BMP4 (200ng/ml) demonstrates induction of SHH. B. qRT-PCR analysis of ovarian cancer line COV318 treated with BMP4 demonstrates induction of IHH. C. Induction of SHH was verified at the protein level via western blot. D. qRT-PCR analysis of CA-MSCs grown in co-culture with tumor cell lines (SKOV3, CAOV-3 and COV318) for 5 days \pm IPI-926 demonstrates BMP4 induction which is abrogated by IPI-926. E. i) qRT-PCR analysis of SKOV3 and CAOV-3 cells grown in co-culture with CA-MSCs demonstrate tumor SHH induction blocked by IPI-926, ii) qRT-PCR analysis of COV318 cells demonstrate IHH induction with CA-MSC co-culture decreased by IPI-926. F. qRT-PCR analysis of average BMP4 expression of CA-MSCs grown in co-culture with SKOV3 or CAOV-3 cells demonstrating decreased BMP4 induction with the SMO inhibitor LDE225 or a BMP4 blocking antibody. G. qRT-PCR analysis of average SHH induction of SKOV3 or CAOV-3 cells co-cultured with CA-MSCs demonstrating decreased SHH induction with LED225 or a BMP4 blocking antibody. Error bars=standard error of the mean. 
only indirect cell/cell contact therefore interactions based on secreted factors were assessed. Cells were cocultured for 5 days \pm IPI-926. Cells were harvested from their respective chambers (CA-MSCs in the upper well, tumor cells in the lower well) and analyzed via qRTPCR to determine levels of BMP4 in CA-MSCs and $H H$ in tumor cells. Co-culture resulted in clear induction of BMP4 in CA-MSCs that was decreased in the presence of IPI-926 (Figure 3D). Likewise, SKOV3 and CAOV3 tumor cells demonstrated significant induction of $\mathrm{SHH}$ while COV318 cells demonstrated significant induction of $\mathrm{IHH}$ (Figure 3E). IPI-926 diminished both $\mathrm{SHH}$ and $\mathrm{IHH}$ induction though effects on $\mathrm{IHH}$ induction were more modest (Figure 3Eii). IPI-926 treatment of CA-MSCs grown in single culture did not affect BMP4 expression levels or cellular viability. Analogously, IPI-926 treatment of tumor cells grown alone had no effect on tumor cell $H H$ expression or cellular viability (Supplemental Figure 2). Similarly, another SMO inhibitor, LDE-225, and a BMP4 blocking antibody were used in the co-culture system (with SKOV3 and CAOV-3 tumor cells) and both demonstrated a reduction in CA-MSC derived BMP4 and tumor derived $\mathrm{HH}$ (Figure 3F, 3G). These findings indicate a tumor/MSC HH/BMP4 signaling loop.

\section{Inhibition of $\mathrm{HH}$ signaling blocks the pro- tumorigenic effects of CA-MSCs}

We previously demonstrated that CA-MSCs significantly promote tumor growth in a BMP2/4dependent manner. We therefore investigated whether disruption of the HH:BMP4 signaling loop with a $\mathrm{HH}$ inhibitor could alter the pro-tumorigenic effects of CAMSCs. We created xenografts using SKOV3 cells alone, SKOV3 + A-MSCs and SKOV3 + CA-MSCs. Mice were treated with IPI-926 $(20 \mathrm{mg} / \mathrm{kg}$ daily via IP injection for 21 days) or vehicle control. Mice were sacrificed when tumor volumes reached size criteria or treatment was complete. Consistent with our previous report [14], untreated SKOV3+CA-MSC tumors grew significantly faster than SKOV3+A-MSC or SKOV3 alone tumors (Figure 4A and Supplemental Figure 3A). Surprisingly, IPI-926 treatment completely abolished the growth advantage provided by CA-MSCs (Figure 4A and Supplemental Figure 3B). IPI926 had no effect on the growth of SKOV3 alone tumors, highlighting a critical role of human CA-MSCs in $\mathrm{HH}$ mediated tumorigenesis (Figure 4A).

Confirming on-target effects of IPI-926, western blot analysis demonstrated clear decreases in GLI1 levels in IPI-926 treated tumors consistent with inhibition of canonical HH signaling (Figure 4B). As predicted, BMP4 levels are highest in SKOV3+CA-MSC tumors. Supporting a positive feedback loop between tumor derived $\mathrm{HH}$ and CA-MSC derived BMP4, there was a 3-fold reduction in BMP4 protein levels in SKOV3+CA-MSC tumors treated with IPI-926 compared to SKOV3+CA-MSC untreated tumors (Figure 4B). Likewise, $\mathrm{SHH}$ protein levels were also reduced (4-fold) in SKOV3+CA-MSC tumors treated with IPI-926 compared to untreated tumors.

Histologic analysis of paraffin embedded tumors demonstrated significant differences in the amount of stroma in CA-MSC containing tumors $(\sim 17$ fold increase compared to SKOV3 alone tumors) (Figure 4C, 4D). This was also observed to a lesser extent with A-MSC containing tumors ( $\sim 5$ fold increase). For CA-MSC containing tumors, treatment with IPI-926 significantly reduced the amount of tumor stroma (Figure 4C, 4D). This suggests that $\mathrm{HH}$ signaling affects MSC contribution to tumor stromal elements.

\section{HH inhibition blocks CA-MSC mediated increase in cancer stem cell-like cell percentage}

We previously demonstrated that CA-MSCs (and to a lesser extent A-MSCs) increase the percentage of $\mathrm{ALDH}^{+}$ cancer stem cell-like cells (CSCs) [14, 28]. Evaluation of the tumor xenografts above demonstrated that, consistent with previous results, there is a significant increase in the percentage of $\mathrm{ALDH}^{+}$cells in the SKOV3+CA-MSC tumors compared to SKOV3 alone tumors. This increase in $\mathrm{ALDH}^{+}$cells is completely blocked with IPI-926 treatment (Figure 4E). SKOV3+A-MSC tumors also demonstrate a modest increase in the percentage of $\mathrm{ALDH}^{+}$cells which is blocked with IPI-926 treatment (Figure 4E). IPI-926 treated SKOV3 alone tumors demonstrated no statistically significant change in the percentage of $\mathrm{ALDH}^{+}$cells. The increase in $\mathrm{ALDH}^{+}$cells is not primarily related to $\mathrm{ALDH}^{+}$ MSCs; when dsRed labeled MSCs were co-grown with SKOV3 cells, dsRed ${ }^{+}$cells represented $\sim 1.2 \%$ of all $\mathrm{ALDH}^{+}$cells thus MSC are not significantly impacting the observed differences in $\mathrm{ALDH}^{+}$cells between groups (Supplemental Figure 3C).

\section{HH inhibition blocks CA-MSC induced chemotherapy resistance in ovarian tumor cells in vitro and in vivo}

Given CA-MSCs can differentiate into distinct stromal cells (such as cancer associated fibroblasts and adipocytes) which promote chemotherapy resistance, and CA-MSCs increase ALDH+ CSCs which are chemotherapy resistant [28], we hypothesized that CA-MSCs would significantly enhance ovarian tumor chemotherapy resistance. We therefore investigated the role of CA-MSCs and the tumor/stromal $\mathrm{HH} /$ BMP4 signaling loop in resistance to platinum based chemotherapy, the core of ovarian cancer therapy. We treated GFP-labeled CAOV-3 cells grown in (i) direct coculture with CA-MSCs or (ii) in single culture at equal densities and treated for 48 hours with increasing amounts 


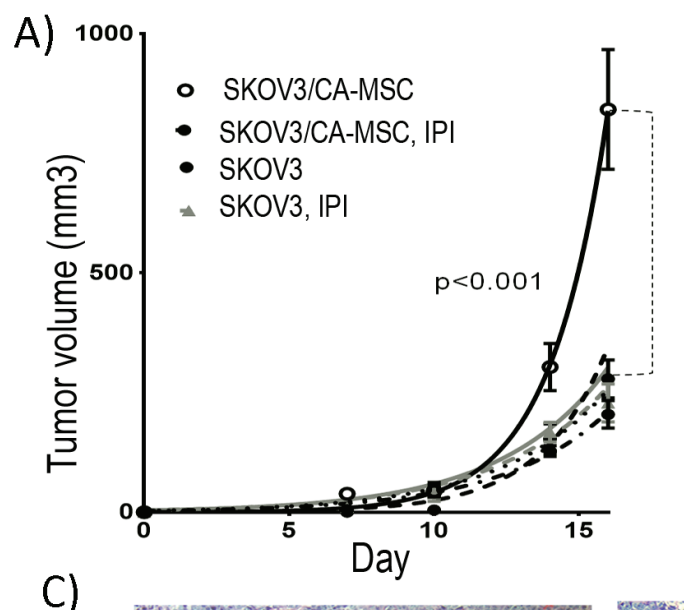

B)

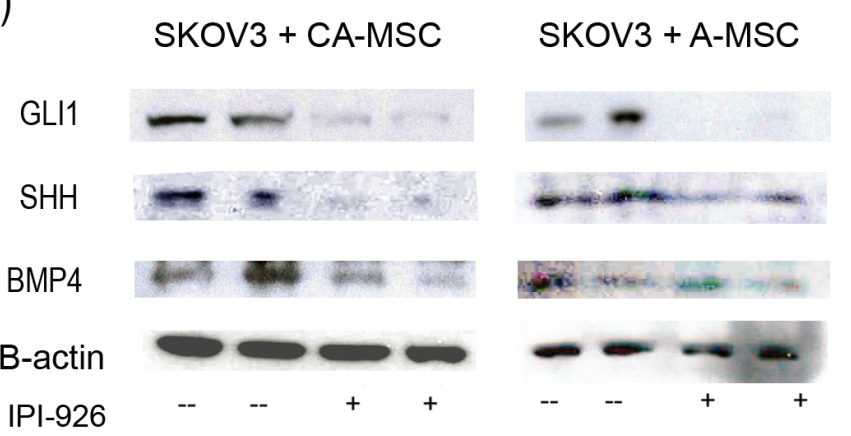

C)
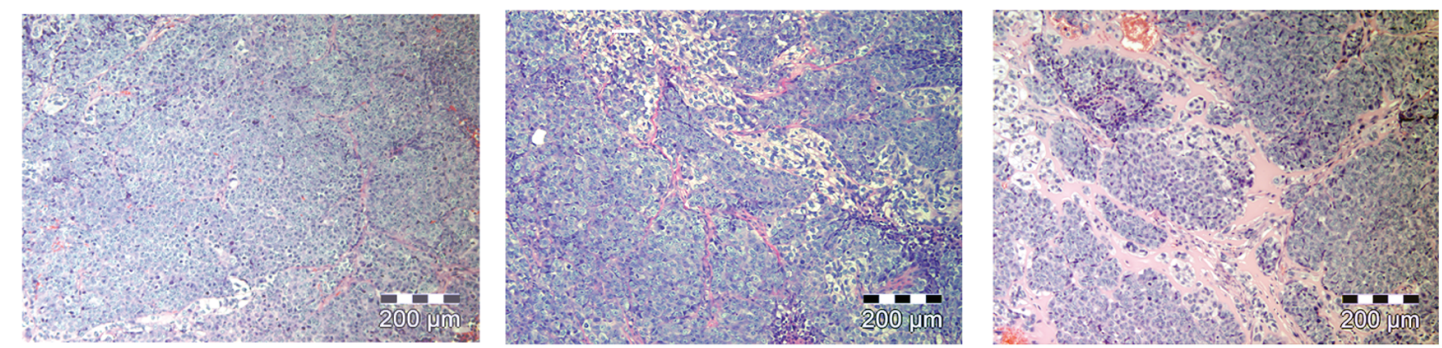

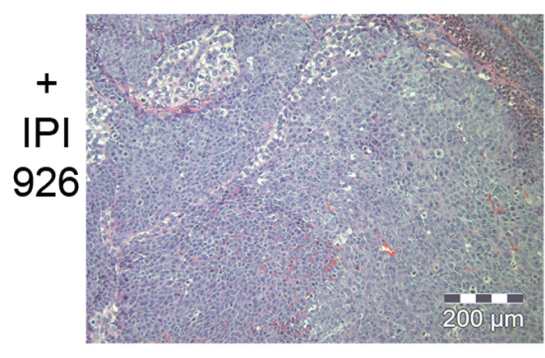

SKOV3

D)

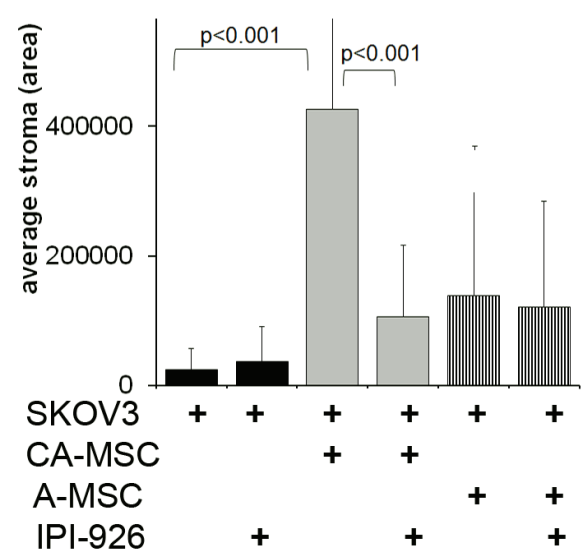

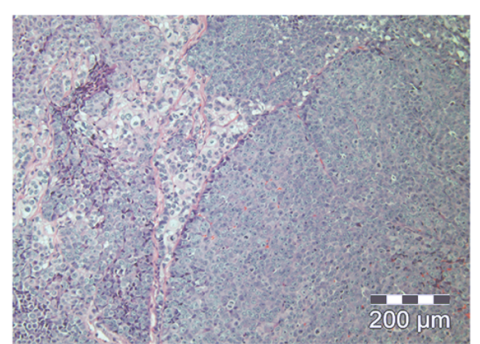

SKOV3+A-MSC

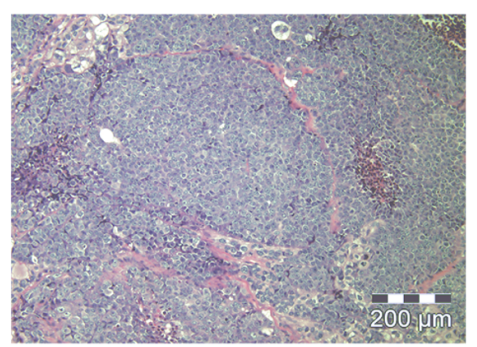

SKOV3+CA-MSC

E)

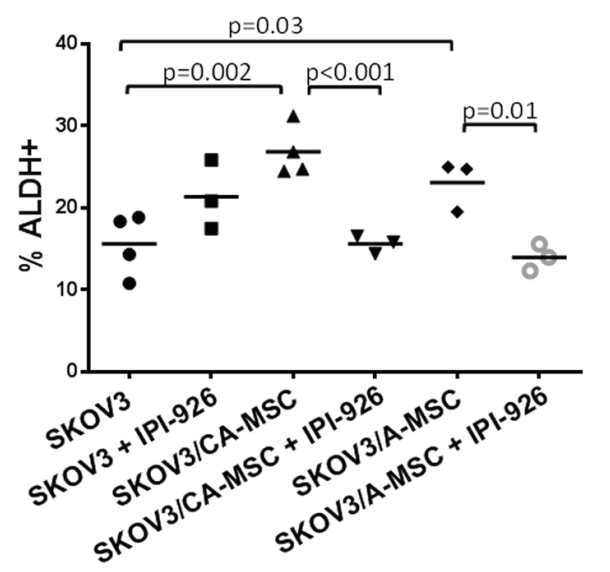

Figure 4: HH inhibition blocks CA-MSC mediated tumor growth promotion and stromal deposition. A. Tumor growth curves of SKOV3 ovarian tumor cells \pm CA-MSCs treated with and without IPI-926 demonstrating HH inhibition blocks CA-MSC-mediated increases in tumor growth. B. Western blot analysis of GLI1, SHH and BMP4 protein levels in SKOV3+CA-MSC and SKOV3+A-MSC tumors \pm IPI-926 treatment confirm on-target effects of HH inhibition and subsequent decreases in BMP4 and SHH. C. Representative H\&E stains of tumors: SKOV3, SKOV3+A-MSC or SKOV3+CA-MSC \pm IPI-926 illustrating IPI-926 blocks MSC-mediated increases in stroma. D. Quantification of stroma in tumors (4 tumors per group, 8 low power sections per tumor). E. Percent ALDH+ cells from SKOV3 \pm CA-MSCs or A-MSCs \pm IPI-926 xenografts demonstrating IPI-926 blocks the CA-MSC-mediated increase in ALDH+ cells (each scatter plot represents an independently analyzed tumor, at least three tumors per group). Error bars=standard error of the mean. 
of cisplatin. Viable cells were analyzed with FACS to distinguish GFP-labeled cancer cells from CA-MSCs. Co-culture of CAOV-3 cells with CA-MSCs, compared to $\mathrm{CAOV}-3$ cells alone, resulted in 3-9 fold increases in tumor cell viability in response to cisplatin (Figure 5A). Addition of IPI-926 drastically decreased CAMSC-mediated CAOV-3 cisplatin resistance while not significantly altering the efficacy of cisplatin in $\mathrm{CAOV}-3$ cells grown in single culture (Figure 5A). In contrast, CAMSCs grown in single culture demonstrated significant resistance to even high doses of chemotherapy (Figure 5B). The sensitivity of CA-MSCs to cisplatin was not significantly altered by co-culture with CAOV-3 cells or the addition of IPI-926 (Figure 5B). Interestingly, a modest decrease in CA-MSCs was seen with IPI-926 + cisplatin in CA-MSC/CAOV-3 co-culture. The ability of IPI-926 to block CA-MSC-mediated chemotherapy resistance was also replicated using co-culture of CA-MSCs and GFPlabeled PEO-1 and Hey1 ovarian cancer cell lines - lines which express both $S H H$ and $I H H$ (Supplemental Figure 4 and data not shown).

We next determined if the same effect on chemotherapy resistance was observed in vivo. CAOV3 cells labeled with luciferase were grown \pm CA-MSCs in the bilateral axilla of NOD/SCID mice and treated with cisplatin $(1 \mathrm{mg} / \mathrm{kg}$ weekly for 3 weeks) or vehicle control. As expected, cisplatin significantly reduced the growth of CAOV-3 tumors (Figure 5C). Once again the addition of CA-MSCs to CAOV-3 tumors significantly increased growth relative to $\mathrm{CAOV}-3$ cells grown alone. Importantly, in the presence of CA-MSCs, CAOV-3 cells no longer demonstrated a significant response to cisplatin (Figure 5C). In fact CAOV-3/CA-MSC tumors treated with cisplatin demonstrated greater growth than untreated CAOV-3 cells grown alone (Figure 5C). To ensure changes in tumor volume were not due to overgrowth of the CA-MSC cells, bioluminescence data was also captured to assess the luciferase labeled CAOV-3 fraction. Bioluminescence measurements were consistent with tumor volume measurement indicating the change in tumor size corresponds with change in tumor cell volume (Supplemental Figure 5A).

To assess the impact of $\mathrm{HH}$ inhibition on CAMSC-mediated chemotherapy resistance, CAOV-3 cells \pm CA-MSCs in were injected into the bilateral axilla of NOD/SCID mice. Tumors were treated with cisplatin as described above (starting on day 7) \pm daily treatment of IPI-926 $(20 \mathrm{mg} / \mathrm{kg} /$ day starting on day 5 after injection and continuing for 21 days). Cisplatin treated CAOV-3/ CA-MSC tumors grew significantly faster than cisplatin treated CAOV-3 alone tumors. The addition of IPI-926 to cisplatin treatment of CAOV-3 alone tumors had no impact on tumor growth. However, IPI-926 with cisplatin lead to a striking decrease in the growth of CAOV-3/ CA-MSC tumors with 2 out of 8 tumors failing to initiate (engraftment rates were 100\% in all other groups) (Figure
5D).

To assess the impact of $\mathrm{HH}$ inhibition on established tumors, once tumors from mice bearing CAOV-3/CAMSC tumors treated with cisplatin reached $\sim 300 \mathrm{~mm} 3$ in volume, mice were randomized and then retreated with (i) cisplatin alone (1mg/kg weekly for up to 3 weeks) or (ii) cisplatin with IPI-926 (starting three days prior to the first cisplatin dose). Cisplatin treatment alone had no impact on tumor growth indicating chemotherapy resistance. In contrast, retreatment with cisplatin + IPI926 lead to not only cessation in tumor growth but to tumor regression while tumors in mice retreated with cisplatin alone continued to grow rapidly (Figure 5E). This demonstrates that not only does blocking $\mathrm{HH}$ signaling lead to prevention of CA-MSC mediated chemotherapy resistance when tumors are small or just starting to engraft, but also significantly impacts tumors which have been firmly established and have been previously treated with chemotherapy.

Analysis of tumor ALDH expression was consistent with our previous findings with SKOV3 xenografts, demonstrating increases in the percentage of $\mathrm{ALDH}^{+}$ cells in CA-MSC containing tumors which is decreased in tumors treated with IPI-926 (Figure 5F). Histologic analysis demonstrates that CA-MSC containing tumors have significantly higher microvessel density (as determined through quantification of human and mouse CD31 positive vessels per high power field) (Figure 5G, 5Hii). IPI-926 treatment blocked this increase in blood vessel density. Likewise, CA-MSC containing tumors had significantly more alpha-smooth muscle actin ( $\alpha \mathrm{SMA})$ positive cells than CAOV-3 cells alone and this effect was decreased with IPI-926 treatment (Figure 5G, 5Hi). Costaining with an anti-human mitochondrial antibody (anti$\mathrm{hMt}$ ) demonstrated that the majority of $\alpha \mathrm{SMA}$ positive cells within CA-MSC-containing tumors are of human origin and therefore likely represent differentiated CAMSCs. aSMA positive cells within the CAOV-3 alone tumors did not co-stain with anti-hMt and are therefore likely of murine origin. Also of note, the staining pattern of $\alpha$ SMA in CAOV-3 alone tumors is largely perivascular and likely to represent vascular associated pericytes whereas aSMA positive cells in the CA-MSC containing tumors, in addition to being found perivascularly, were also present in large extra-vascular bands consistent with activated fibroblasts. This is consistent with our findings in SKOV3 xenografts which demonstrated clear, gross changes in the amount of tumor stroma in CA-MSC containing tumors which is reversed with $\mathrm{HH}$ inhibition.

Collectively, our results demonstrate that $\mathrm{HH}$ pathway inhibition prevents CA-MSC-mediated tumor growth promotion and enhancement of chemotherapy resistance. This points to a tumor/CA-MSC HH/BMP4 signaling loop as a critical mediator of the pro-tumorigenic effects of CA-MSCs. 

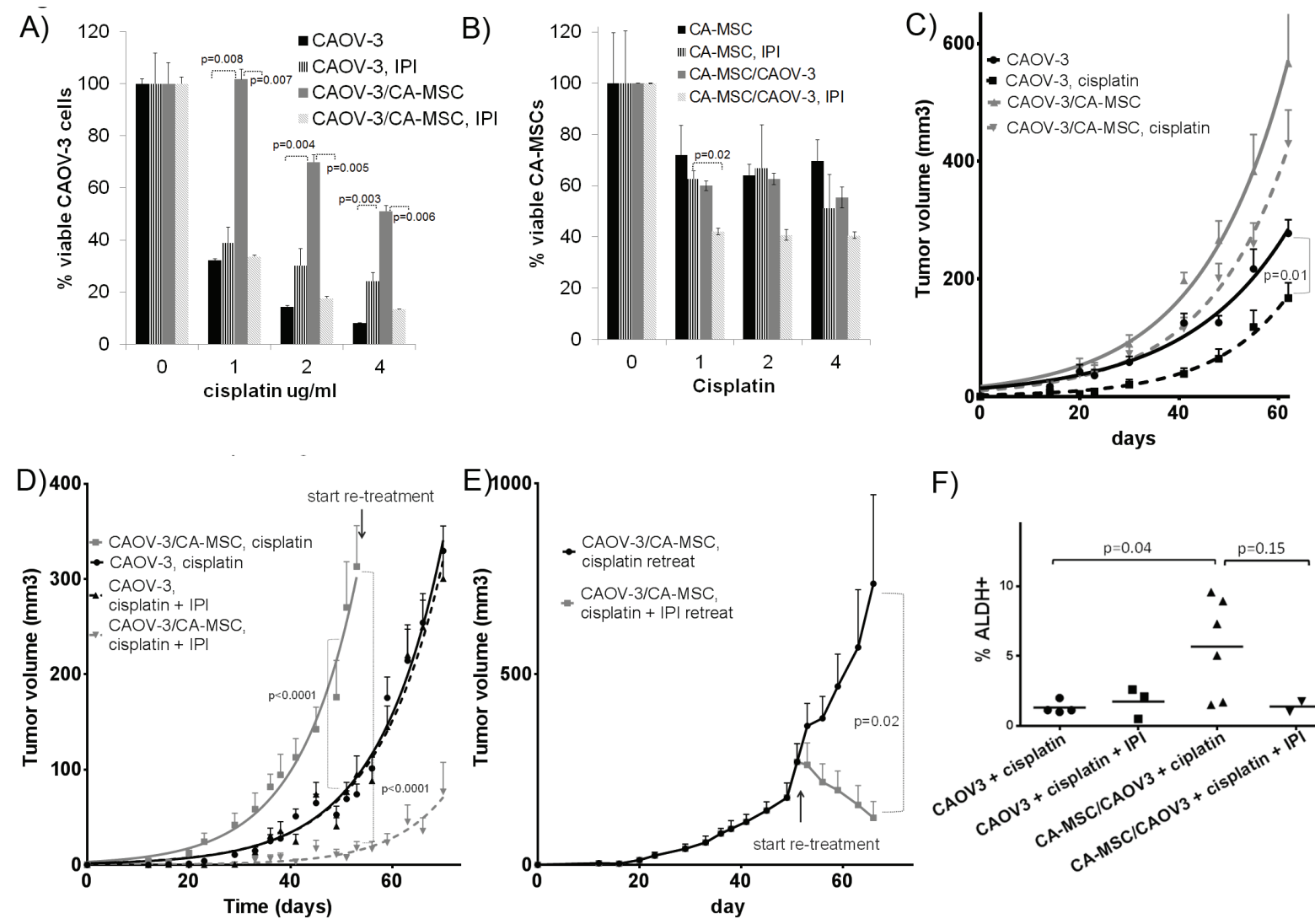

F)
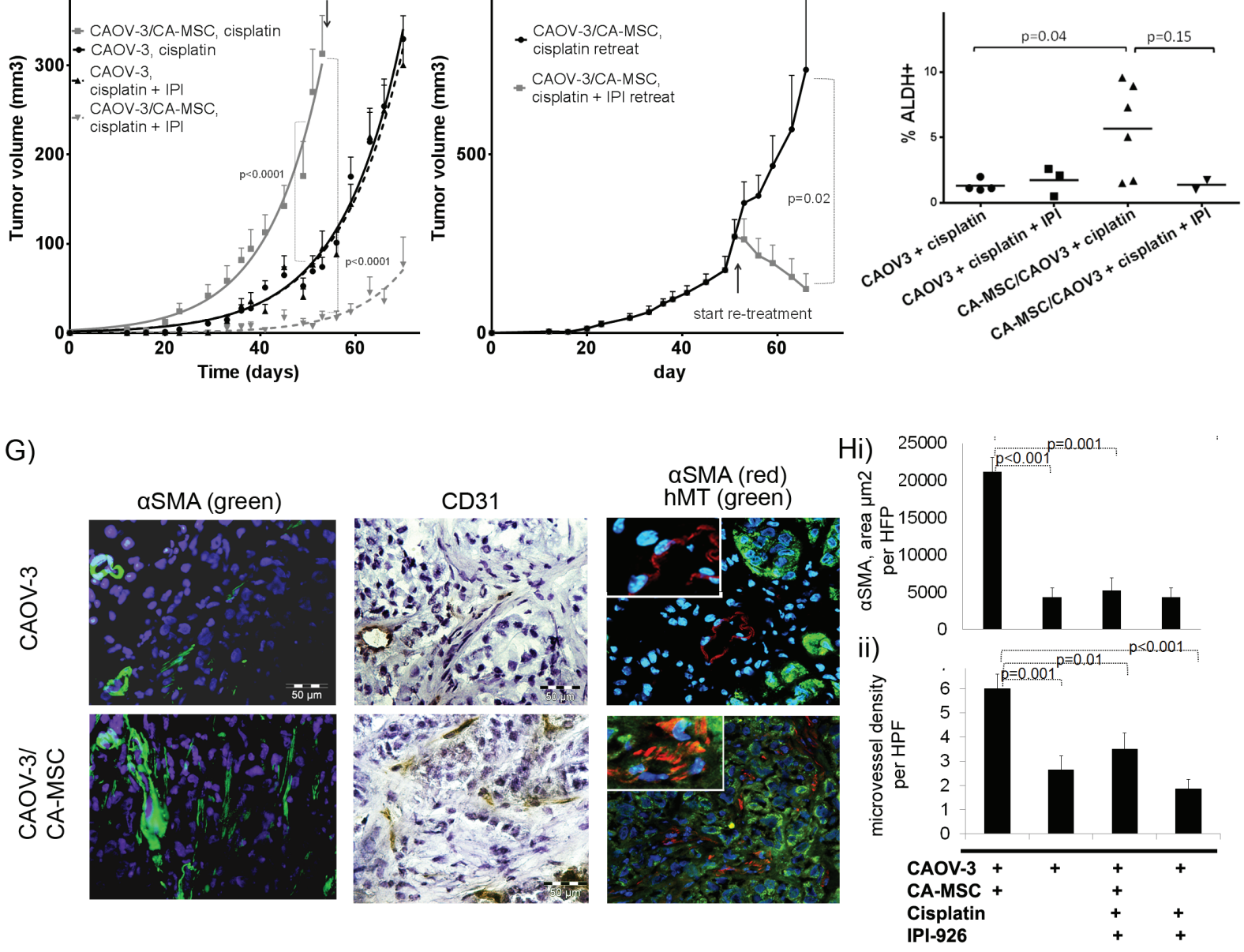

Figure 5: CA-MSCs promote chemotherapy resistance which can be reversed with $\mathrm{HH}$ inhibition. A.-B. In vitro co-culture of GFP-CAOV-3 tumor cells \pm CA-MSCs treated with cisplatin \pm IPI-926, A. co-culture with CA-MSCs enhance tumor cell platinumresistance and is reversed with IPI-926, graph represents \% viable GFP-CAOV-3 cells normalized to $0 \mathrm{ug} / \mathrm{ml}$ cisplatin group. B. CA-MSCs demonstrate cisplatin-resistance is not significantly altered by co-culture with tumor cells or co-treatment with cisplatin + IPI-926, graph represents \% viable CA-MSCs normalized to $0 \mathrm{ug} / \mathrm{ml}$ cisplatin group. C. Growth curve of CAOV-3 and CAOV-3/CA-MSC xenografts treated \pm cisplatin demonstrating CA-MSCs promote platinum-resistance in vivo D. Growth curve of CAOV-3 and CAOV-3/CA-MSC xenografts treated with cisplatin \pm IPI-926 demonstrating IPI-926 prevents CA-MSC-mediated platinum-resistance. E. Growth curve of CAOV-3/CA-MSC xenografts retreated with cisplatin \pm IPI-926 starting on day 53 demonstrating IPI-926 reverses chemotherapy resistance in established tumors. F. Percent ALDH+ cells from CAOV-3 \pm CA-MSCs xenografts treated with cisplatin \pm IPI-926 demonstrating IPI-926 blocks CA-MSC-mediated increases in ALDH+ cells. G. IF of CAOV-3 and CAOV-3/CA-MSC xenografts with anti-alpha smooth muscle actin ( $\alpha$ SMA) (green), anti- $\alpha$ SMA (red) /anti-human mitochondrial antibody (hMT-green) demonstrating increased human stroma in CAMSC-containing tumors and IHC of anti-CD31 (human/mouse). H. i) Quantification of aSMA per high power field (HPF) demonstrating IPI-926 blocks CA-MSC-mediated increases in fibroblasts ii) Quantification of microvessel density per HPF illustrating IPI-926 blocks CA-MSC-mediated increase in microvessel density. Error bars=standard error of the mean. 


\section{DISCUSSION}

Increased HH signaling is correlated with poor outcomes in ovarian cancer [19]. Further, HH signaling is increased at the time of disease recurrence indicating the importance of this pathway in ovarian cancer [20]. Previous work indicates that $\mathrm{HH}$ acts primarily on the stroma [18]. However, which cells in the stroma HH acts upon was unclear. We now show that CA-MSCs are a critical target for stromal $\mathrm{HH}$ activation. $\mathrm{HH}$ activation of CA-MSCs results in the previously reported increased CAMSC expression of BMP4 [14]. BMP4 in turn increases tumor $H H$ expression, thus creating a positive feedback loop (Figure 6). We find this loop is critical to CAMSC-mediated increases in tumor growth and promotes chemotherapy resistance associated with increases in $\mathrm{ALDH}^{+}$ovarian cancer stem-like cells. Interruption of this signaling loop with pharmacologic $\mathrm{HH}$ inhibition prevents the growth-promoting effects of CA-MSCs in vivo, reverses chemotherapy resistance and normalizes CSC percentages, indicating the importance of $\mathrm{HH}$ signaling to the pro-tumorigenic function of CA-MSCs. Our work is consistent with studies indicating $\mathrm{HH}$ inhibition can overcome stromal mediated chemotherapy resistance [3]. These prior studies found $\mathrm{HH}$ inhibition could overcome taxane but not platinum resistance. Platinum is the cornerstone of ovarian cancer therapy. Our work shows that $\mathrm{HH}$ inhibition can overcome platinum resistance even in well-established tumors.

\section{Incorporating CA-MSC in tumor xenografts}

Our work is unique from the prior studies of $\mathrm{HH}$ as CA-MSCs create a 'humanized' tumor stroma. Unlike most ovarian cancer cell line xenografts and later passage PDX, CA-MSC containing tumors have a robust human stroma more analogous to that seen in patient tumors. This is important as we observed minimal effectiveness of $\mathrm{HH}$ inhibition, either alone or in combination with chemotherapy, in the standard human cell line xenograft model. However we observed robust response in tumors with humanized stroma. This indicates the importance of studying therapeutics in the context of a human stroma.

We previously demonstrated human fibroblast, adipocyte and osteoblast mRNA expression in xenografts containing human CA-MSCs. We now use IHC analysis with anti-human mitochondria antibodies to confirm CAMSC containing xenografts have a predominantly human tumor stroma. CA-MSC containing xenografts have increased numbers of $\alpha \mathrm{SMA}^{+}$activated myofibroblasts which is prevented by HH inhibition. Additional studies will be necessary to determine the mechanism whereby $\mathrm{HH}$ inhibition reverses CA-MSC mediated stromal formation. It is interesting to note that CA-MSCs by themselves are highly chemotherapy resistant. Thus CA-MSCs are likely preserved following chemotherapy and could support the expansion and ultimately the drug resistance of residual cancer cells.
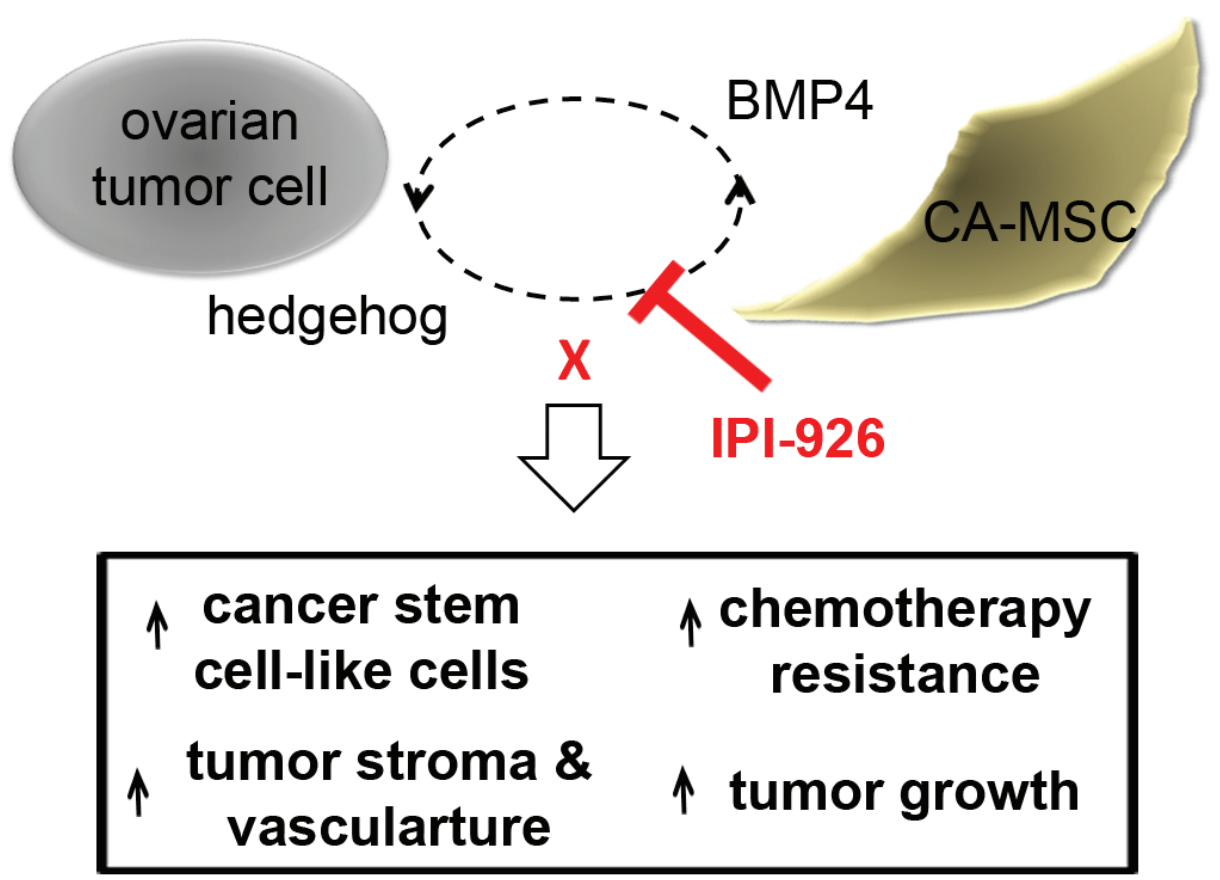

Figure 6: Schematic of ovarian tumor cell:CA-MSC hedgehog:BMP4 feed forward loop. Ovarian tumor derived HH induces increased expression of BMP4 in CA-MSCs. CA-MSC derived BMP4 feeds back and induces increased expression of tumor derived HH. Blocking this signaling loop with the HH inhibitor IPI-926 prevents CA-MSC mediated increases in cancer stem cell-like cells, tumor growth, tumor stroma, tumor vasculature and chemotherapy resistance. 


\section{Hedgehog in malignancy}

$\mathrm{HH}$ inhibition is an effective therapeutic approach in both basal cell carcinomas and meningiomas [29-31]. $\mathrm{HH}$ is an important tumor/stroma signaling component in several solid tumors including prostate, colon and pancreatic cancers $[18,32-35]$. However, $\mathrm{HH}$ does not promote growth in all tumor models. Studies in bladder cancer suggest that HH:BMP tumor/stromal signaling restricts cancer growth [23]. Similarly, recent work in a pancreatic cancer model demonstrates a tumor growth inhibitory role for $\mathrm{HH}$ signaling with concurrent increases in tumor stromal elements [33]. Indeed, recent trials in colon and pancreatic cancer demonstrated no benefit and in one pancreatic trial, a possible trend toward harm with hedgehog inhibition [22, 36, 37]. In contrast, a $\mathrm{HH}$ inhibitor maintenance trial in ovarian cancer demonstrated no evidence of detriment [38] with a trend towards improvement in progression free survival. One potential explanation for the differences observed for $\mathrm{HH}$ inhibitors in ovarian cancer vs. colon, bladder, and pancreatic cancers is the developmental origin of the distinct tissues; embryologically, ovarian/fallopian tube epithelium is mesodermal in origin. In contrast pancreatic, colon, and bladder epithelial cells are endodermal in origin. During development, HH signaling has widely contrasting tissuespecific functions therefore it would not be surprising that $\mathrm{HH}$ signaling may act in a completely different manner in cells derived from different primary germ layers [39]. Further highlighting the complexity of $\mathrm{HH}$ signaling, we demonstrate that both tumor derived SHH and IHH form a signaling loop with CA-MSC-derived BMP4. Interestingly, in vitro SMO inhibition with IPI-926 more effectively disrupted the SHH/BMP4 loop as compared to the IHH/BMP4 loop. Additional work will be necessary to determine if this relates to currently undefined differences in SHH and IHH signaling or alternate pathways promoting tumor cell IHH secretion.

As noted above, $\mathrm{HH}$ inhibitors have not demonstrated significant clinical activity as single agents in ovarian cancer [38]. It has been suggested this trial failed as it did not select patients based on tumor $\mathrm{HH}$ expression [40]; the rate of $\mathrm{HH}$ activation in ovarian cancers $(25-70 \%)$ remains controversial $[19,40,41]$. Our study suggests greatest potential clinical benefit in combining $\mathrm{HH}$ inhibition with chemotherapy. Indeed targeting HH may be a strategy to reverse platinumresistance, an inevitable and deadly step in the progression of ovarian cancer.

\section{BMP4 and ovarian cancer}

While a majority of the studies presented here, due to availability of clinically relevant inhibitors, focused on HH inhibition, BMP4 is also a critical component of this signaling loop. A BMP4 blocking antibody mimicked $\mathrm{HH}$ inhibition in vitro. Several studies have supported a critical role for BMP4 in ovarian cancer. BMP4 promotes migration and metastasis in ovarian cancer [42] and BMP4 stimulation of ovarian cancer cells can activate ID3 protooncogene expression [43]. We previously demonstrated, and confirmed here, that BMP signals from CA-MSCs increase the number of $\mathrm{ALDH}^{+} \mathrm{CSCs}$. We have also recently reported $\mathrm{BMP} 2$ as a regulator of CSC division increasing the proportion of $\mathrm{ALDH}^{+}$cells [44]. Consistent with prior studies [45] [14], our data also demonstrate a modest increase in $\mathrm{ALDH}^{+}$tumor cells after co-growth with normal adipose-derived MSCs (which at baseline have significantly lower levels of BMP4 compared to CAMSCs). This may be due to alternate signaling pathways such as the IL6/CXCL7 loop reported in breast cancer [45]. Alternatively, this may be due to the development of a CA-MSC-like expression profile (with increasing levels of BMP2 and 4) in normal adipose-derived MSCs after long periods of tumor stimulation. Indeed, our previous work demonstrated tumor cell conditioning over time leads to changes in the overall expression profile of normal tissue MSCs yielding increases in BMP family proteins [14]. Further, IPI-926 blocks the normal MSCmediated increase of $\mathrm{ALDH}^{+}$tumor cells arguing for the development of a tumor:MSC HH:BMP signaling loop over time in normal MSCs.

While clearly important in ovarian cancer, effective clinical targeting of the BMP pathway has proven challenging. The identification of $\mathrm{HH}$ as a vital modulator of stromal BMP4 production provides a novel method to target BMP-associated tumorigenesis.

\section{MSCs and ovarian cancer}

While controversy remains regarding the role of MSCs and cancer in general, numerous studies in ovarian cancer report a pro-tumorigenic role of MSCs. MSCs can directly impact the cancer cells to increase the growth of cancer stem cell-like cells [14], promote an epithelial mesenchymal transition [46], and increase resistance to apoptosis [47]. MSCs can also promote cancer cell chemotherapy resistance, even in the setting of hyperthermic therapy [48]. MSC are also reported to promote ovarian cancer invasive capacity and broadly impact the transcriptional profile of cancer cells to create a pro-metastatic phenotype [48, 49]. Interestingly, the impact of MSCs on cancer cells can be both via cytokine signaling as described here, and the exchange of cellular materials via exosomes $[50,51]$. Similarly, MSCs can impact the host cells in the tumor microenvironment promoting ovarian cancer growth via increased angiogenesis [52] and suppression of the anti-tumor immune responses [53]. Taken together this data strongly supports MSCs as a therapeutic target in ovarian cancer. Given $\mathrm{HH}$ inhibition in vivo completely eliminated many 
of the pro-tumorigenic effects of CA-MSCs including increased angiogenesis, chemotherapy resistance, and increased tumor 'stemness' HH signaling may be a master regulator of CA-MSC function in ovarian cancer.

\section{CONCLUSION}

In summary, the identification of a signaling loop with tumor derived $\mathrm{HH}$ and CA-MSC derived BMP4 adds further support to the importance of the tumor microenvironment and stromal signaling. Our findings help to elucidate the mechanism of CA-MSCs protumorigenic functions. We demonstrate the critical importance of evaluating stromal targeted therapeutics in the presence of a human tumor stroma. Finally, these studies add to growing literature supporting the clinical use of $\mathrm{HH}$ inhibitors in ovarian cancer particularly in combination with chemotherapy and may specifically help revert platinum resistant disease to platinum sensitive disease.

\section{MATERIALS AND METHODS}

\section{Tissue harvesting and culture}

Patients samples were obtained in accordance with a protocol approved by the University of Michigan's IRB (IRB no HUM0009149). Tissue was processed for RNA isolation as previously described [54]. MSCs were isolated as previously described [14]. Briefly, to isolate CA-MSCs primary patient derived tumor tissue was plated in supplemented MEBM media and MSCs were selected for plastic adherence. CA-MSCs were characterized by cell surface marker expression (positive for CD105, CD90, CD73, CD44; negative for CD34, CD24, CD45) and their ability to differentiate into adipocytes, osteocytes or fibroblasts (following guidelines presented by The International Society for Cellular Therapy on the minimal criteria for defining multipotent mesenchymal stem cells[15]). A summary of CA-MSC cell surface marker expression and differentiation is provided in Supplemental Figure 6. Adipocyte and osteocyte differentiation was stimulated using differentiation media from StemCell technologies, (Vancover, BC). Fibroblast/myofibroblast differentiation was performed through prolonged indirect co-culture with ovarian tumor cells. Normal healthy donor-derived MSCs were purchased (for adipose MSCs) (Invitrogen, Grand Island, NY) or derived from normal omental or normal ovary surgical samples (using the same procedure as above for CA-MSC isolation from tumor tissue). Adipose, normal ovary and patient derived CAMSCs were maintained in culture as previously described [14]. Mesenchymal stem cells were used at passage 8 or below. Ovarian cancer cell lines SKOV3, CAOV-3,
COV318, Hey1 and PEO1 were obtained from ATCC and cultured in RPMI supplemented with $10 \%$ heat-inactivated FBS and 1\% penicillin/streptomycin (SKOV3, Hey1) and DMEM supplemented with 10\% heat-inactivated FBS and $1 \%$ penicillin/streptomycin (CAOV-3, COV318, PEO1).

\section{Gli1 $^{\text {lac } Z}$ mice}

Gli ${ }^{\text {lacZ }}$ reporter mice were treated for 5 days with anti-mouse CD3e (clone 2c-11, Ebioscience San Diego, CA) antibody to reduce immune rejection of tumor cells. ID8 xenografts were created by injecting $10 \times 10^{6}$ cells into the bilateral flanks of treated animals. ID8 xenograft tissue was obtained at time of sacrifice and B-Galactosidase staining was performed on tissues fixed in 4\% PFA and embedded in OCT for cryosectioning [25]. Normal ovarian tissue was obtained from non-T cell depleted animals and processed as above. Quantification of B-Galactosidase staining was performed using ImageJ thresholding analysis [55]. Three independent sections of tumor and non-tumor stroma were used for quantification.

\section{Quantitative real-time PCR}

RNA was isolated with the RNeasy Mini Kit (Qiagen, Hilden, Germany) and on-column DNase treatment (Qiagen, Hilden, Germany). RNA concentration was determined with NanoDrop ND-1000 Spectrophotometer. cDNA was synthesized with the SuperScript III First-Strand Synthesis System for RT-PCR (Invitrogen, Grand Island, NY) as previously described [56]. SYBR green-based RT-PCR was performed using the 7900HT Sequence Detection System (Applied Biosystems, Foster City, California) and respective primers. The comparative $\mathrm{Ct}$ method was used for data analysis, HPRT or GAPDH were used as the comparator genes.

\section{Immunoblotting}

Portions of whole tumor or cell pellets were homogenized in RIPA buffer (Pierce, Rockford, IL) with complete protease inhibitor (Roche, Basel, Switzerland). Insoluble material was removed by centrifugation at $16,000 \mathrm{~g}$ at $4^{\circ} \mathrm{C}$ for $15 \mathrm{mins}$. Protein concentrations were determined using the Bradford Protein Assay Kit (BioRad, Hercules,CA). Equal amounts of protein were separated on 4-12\% NuPAGE SDS gel (Invitrogen, Grand Island, NY) and transferred onto a PVDF or nitrocellulose membrane. Antibodies for western blot analysis include anti-BMP4 (1:1000 dilution, Abcam, Cambridge, England), anti-SHH (1:500, 5E1, Developmental Studies Hybridoma Bank, Iowa City, IA), anti-Gli1 (1:500, PCRPGLI1-1A1, Developmental Studies Hybridoma Bank, 
Iowa City, IA) and anti-B-actin (1:10,000 dilution, SigmaAldrich, St. Louis, MO). Bands were visualized using the ECL Kit (Pierce, Rockford, IL).

\section{In vitro SHH or TCM treatment of MSCs}

Adipose, normal ovary and CA-MSCs plated at $1 \times 10^{5}$ cells/6well in serum free supplemented MEBM media were treated with recombinant SHH $(10-100 \mathrm{ng} / \mathrm{ml})$ (R\&D systems, Pittsburg, PA) for $24 \mathrm{hrs}$ then processed for qRT-PCR as described above. For TCM, media was collected from tumor cell lines grown to $60 \%$ confluence after 3 days and centrifuged for $15 \mathrm{~min}$ at $3500 \mathrm{rpm}$ to remove cellular debris. MSCs were treated with $\mathrm{TCM} \pm$ IPI-926 (10nM) for 3 days then cells were processed for qRT-PCR or immunoblotting.

\section{In vitro BMP4 treatment of tumor cells}

SKOV3, CAOV-3 and COV318 cells were plated $\left(2 \times 10^{5}\right.$ cells $/ 6$ well dish) in serum-free media treated with 200ng/ml recombinant BMP4 (R\&Dsystems, Pittsburg, PA) for 16 and 48hours. Cells were then processed for RTPCR or immunoblotting.

\section{CA-MSC/tumor cell co-culture}

SKOV3, CAOV-3, or COV318 were grown in coculture with CA-MSCs using $24 \mathrm{~mm}$ polystyrene transwell inserts, 0.4um pore (Sigma Aldrich, St. Louis, MO). CAMSCs $\left(5 \times 10^{4}\right.$ cells) were seeded onto the top chamber in $1.5 \mathrm{ml}$ supplemented MEBM media and tumor cells $\left(5 \times 10^{4}\right.$ cells) were seeded into the lower chamber in $2.5 \mathrm{ml}$ RPMI or DMEM $\pm 20 \mathrm{nM}$ IPI-926 or LDE225 (APExBIO) or the anti-BMP4 blocking antibody (R\&D systems) for 5 days. CA-MSCs and tumor cells grown alone were used as controls.

\section{In vivo mouse MSC/tumor xenografts}

Xenografts containing SKOV3 cells alone $\left(1 \times 10^{6}\right.$ cells), SKOV3 + A-MSCs $\left(0.5 \times 10^{6}\right.$ cells each $)$ and SKOV3 + CA-MSCs $\left(0.5 \times 10^{6}\right.$ cells each $)$ with growth factor reduced matrigel (BD Biosciences, San Jose, CA) were injected into the bilateral axilla of NOD-SCID mice. After 5 days (to allow for tumor engraftment), half of the mice were treated with IPI-926 (Active Biochem, Hamburg, Germany) (20mg/kg daily via IP injection for 21 days as previously described by Lee et al. [57]). Mice were sacrificed when tumor burden exceeded $1500 \mathrm{~mm}^{3}$. Tumor volume was calculated using the modified ellipsoid formula $\left(\mathrm{L}^{*} \mathrm{~W}^{2}\right) / 2$. Five mice with bilateral axillary xenografts were used per treatment group ( $n=10$ tumors per group). Two additional mice were injected with dsRed
MSC/SKOV3 xenografts to serve as controls for FACS analysis below. NOD-SCID mice were maintained in accordance with institutional policies and all studies were performed with approval of the University Committee on Use and Care of Animals of the University of Michigan.

\section{In vitro chemotherapy resistance assays}

CAOV-3, PEO1 or Hey1 cells labeled with GFP via lentiviral transduction were grown in co-culture with CA-MSCs in a 1:1 ratio with a total of 20,000 cells $/ 24$ well dish or in single culture with 20,000 cells/well and treated with cisplatin \pm IPI-926 $(20 \mathrm{nM})$ for $24-48$ hours. The number of viable GFP-tumor cells and CA-MSCs was analyzed via FACS using propidium iodide for viability stain and gating on GFP positive cells (for tumor cell analysis) or GFP negative cells (for CA-MSC analysis).

\section{In vivo chemotherapy resistance}

Xenografts containing luciferase labeled CAOV3 cells alone $\left(1 \times 10^{6}\right.$ cells $)$, CAOV- $3 /$ A-MSCs $\left(0.5 \times 10^{6}\right.$ cells each) and CAOV-3/CA-MSCs $\left(0.5 \times 10^{6}\right.$ cells each) with growth factor reduced matrigel were injected into the bilateral axilla of NOD-SCID mice. After 7 days, half of the mice were treated with cisplatin $(1 \mathrm{mg} / \mathrm{kg}$ weekly x 3 weeks). Bioluminescence was measured at day 40 . Tumor volume measurement and euthanasia criteria were followed as above. Five mice with bilateral axillary xenografts were used per treatment group ( $n=10$ tumors per group).

The experiment was repeated with CAOV-3 cells alone and CAOV-3/CA-MSCs. After 5 days, half of the mice were treated with IPI-926 $(20 \mathrm{mg} / \mathrm{kg}$ daily via IP injection for 21 days). All mice received cisplatin treatment $(1 \mathrm{mg} / \mathrm{kg}$ weekly x 3 weeks starting on day 7 after injection). When the CAOV-3/CA-MSC cisplatin treated tumors reached $\sim 300 \mathrm{~mm} 3$, half of the mice were retreated with cisplatin $(1 \mathrm{mg} / \mathrm{kg}$ weekly for up to 3 weeks) and half were retreated with cisplatin + IPI-926 (20mg/ $\mathrm{kg}$ daily until time of sacrifice). Five mice with bilateral axillary xenografts were used per treatment group $(n=$ 10 tumors per group) except in the CAOV-3/CA-MSC groups which contained 4 mice with bilateral tumors $(n$ $=8$ tumors).

\section{Immunohistochemistry}

Tumors were cryosectioned or paraffin embedded. Paraffin-embedded tissue was H\&E stained at the ULAM Pathology Cores for Animal Research at the University of Michigan and stroma quantified per low-power field (10x). Cryosectioned tumors were fixed and stained with antiCD31 antibody (Dako) or permeablized and stained with 
anti- $\alpha$ SMA antibody- Cy3 (Abcam) and co-stained with mouse anti-human mitochondrial antibody (Life tech) with goat anti-mouse-alexa 488 secondary. CD31 + cells were counted to determine microvessel density per hpf (40x). Anti- $\alpha$ SMA staining was quantified by determining the area of positive staining per hpf (40x). 10 sections from 3 tumors per treatment group were analyzed [58].

\section{FACS}

Xenograft single cell suspensions were analyzed for ALDH expressing cells with the Aldehyde Dehydrogenase-Based Cell Detection Kit as previously described [28] (Stemcell Technologies, Vancouver, Canada). FACS gating was based on live cells (via DAPI) with DEAB control for each sample. At least 3 independent tumors were used for each analysis except for the CAOV-3/CA-MSC+Cis+IPI-926 group in which two tumors were analyzed due to low tumor burden in this group. Flow cytometric analysis was performed on a BD Biosciences FACSCalibur through the University of Michigan Flow Cytometry Core.

\section{Statistics}

All in vitro experiments were repeated independently at least three times with triplicate samples in each experiment unless otherwise stated. Statistical significance was evaluated using a 2-sided student's T-test. For all experiments, $\alpha=0.05$. For animal studies, $n=10$ per group based on final tumor volume of control animals of $\sim 1000 \mathrm{~mm}^{3}$ with an expected standard deviation of $30 \%$. Non-linear regression analysis of tumor growth over time was performed for each group and curves compared to determine statistical significance. In all Figures, error bars represent standard error of the mean of composite values from independent experiments.

\section{ACKNOWLEDGMENTS}

This work was supported in part by the National Institutes of Health New Investigator Innovator Directors Award DP200440377 and 1-R01-CA163345-01. L. Coffman is supported by the Association of American Cancer Institutes Fellowship and American Society of Clinical Oncology's Young Investigator Award. Facilities used in this study were supported in part by the National Institutes of Health through the University of Michigan Cancer Center Support Grant (P30 CA046592).

\section{CONFLICTS OF INTEREST}

The authors have no conflicts of interest to disclose.

\section{REFERENCES}

1. Surveillance E, and End Results (SEER) Program (www. seer.cancer.gov) Research Data (1973-2010), National Cancer Institute, DCCPS, Surveillance Research Program, Surveillance Systems Branch, released April 2013, based on the November 2012 submission.

2. Nieman KM, Kenny HA, Penicka CV, Ladanyi A, BuellGutbrod R, Zillhardt MR, Romero IL, Carey MS, Mills GB, Hotamisligil GS, Yamada SD, Peter ME, Gwin K, et al. Adipocytes promote ovarian cancer metastasis and provide energy for rapid tumor growth. Nature medicine. 2011; 17:1498-1503.

3. Xu L, Deng Q, Pan Y, Peng M, Wang X, Song L, Xiao $\mathrm{M}$ and Wang Z. Cancer-associated fibroblasts enhance the migration ability of ovarian cancer cells by increasing EZH2 expression. International journal of molecular medicine. 2014; 33:91-96.

4. Thibault B, Castells M, Delord JP and Couderc B. Ovarian cancer microenvironment: implications for cancer dissemination and chemoresistance acquisition. Cancer metastasis reviews. 2014; 33:17-39. doi: 10.1007/s10555013-9456-2.

5. Yeung TL, Leung CS, Wong KK, Samimi G, Thompson MS, Liu J, Zaid TM, Ghosh S, Birrer MJ and Mok SC. TGFbeta modulates ovarian cancer invasion by upregulating CAF-derived versican in the tumor microenvironment. Cancer research. 2013; 73:5016-5028.

6. Yang X, Hou J, Han Z, Wang Y, Hao C, Wei L and Shi Y. One cell, multiple roles: contribution of mesenchymal stem cells to tumor development in tumor microenvironment. Cell \& bioscience. 2013; 3:5.

7. Barcellos-de-Souza P, Gori V, Bambi F and Chiarugi P. Tumor microenvironment: bone marrow-mesenchymal stem cells as key players. Biochimica et biophysica acta. $2013 ; 1836: 321-335$.

8. Jung Y, Kim JK, Shiozawa Y, Wang J, Mishra A, Joseph J, Berry JE, McGee S, Lee E, Sun H, Wang J, Jin T, Zhang H, et al. Recruitment of mesenchymal stem cells into prostate tumours promotes metastasis. Nature communications. 2013; 4:1795.

9. Garcia MG, Bayo J, Bolontrade MF, Sganga L, Malvicini M, Alaniz L, Aquino JB, Fiore E, Rizzo MM, Rodriguez A, Lorenti A, Andriani O, Podhajcer O, et al. Hepatocellular carcinoma cells and their fibrotic microenvironment modulate bone marrow-derived mesenchymal stromal cell migration in vitro and in vivo. Molecular pharmaceutics. 2011; 8:1538-1548.

10. Birnbaum T, Roider J, Schankin CJ, Padovan CS, Schichor C, Goldbrunner R and Straube A. Malignant gliomas actively recruit bone marrow stromal cells by secreting angiogenic cytokines. Journal of neuro-oncology. 2007; 83:241-247.

11. da Silva Meirelles L, Chagastelles PC and Nardi NB. 
Mesenchymal stem cells reside in virtually all post-natal organs and tissues. Journal of cell science. 2006; 119:22042213.

12. Crisan M, Yap S, Casteilla L, Chen CW, Corselli M, Park TS, Andriolo G, Sun B, Zheng B, Zhang L, Norotte C, Teng $\mathrm{PN}$, Traas J, et al. A perivascular origin for mesenchymal stem cells in multiple human organs. Cell stem cell. 2008; 3:301-313.

13. Kim SH, Bang SH, Park SA, Kang SY, Park KD, Oh IU, Yoo SH, Kim H, Kim CH and Baek SY. Character comparison of abdomen-derived and eyelid-derived mesenchymal stem cells. Cell proliferation. 2013; 46:291299.

14. McLean K, Gong Y, Choi Y, Deng N, Yang K, Bai S, Cabrera L, Keller E, McCauley L, Cho KR and Buckanovich RJ. Human ovarian carcinoma-associated mesenchymal stem cells regulate cancer stem cells and tumorigenesis via altered BMP production. The Journal of clinical investigation. 2011; 121:3206-3219.

15. Dominici M, Le Blanc K, Mueller I, Slaper-Cortenbach I, Marini F, Krause D, Deans R, Keating A, Prockop D and Horwitz E. Minimal criteria for defining multipotent mesenchymal stromal cells. The International Society for Cellular Therapy position statement. Cytotherapy. 2006; 8:315-317.

16. Verardo R, Piazza S, Klaric E, Ciani Y, Bussadori G, Marzinotto S, Mariuzzi L, Cesselli D, Beltrami AP, Mano M, Itoh M, Kawaji H, Lassmann T, et al. Specific mesothelial signature marks the heterogeneity of mesenchymal stem cells from high-grade serous ovarian cancer. Stem Cells. 2014; 32:2998-3011.

17. Lan Y and Jiang R. Sonic hedgehog signaling regulates reciprocal epithelial-mesenchymal interactions controlling palatal outgrowth. Development. 2009; 136:1387-1396.

18. Yauch RL, Gould SE, Scales SJ, Tang T, Tian H, Ahn CP, Marshall D, Fu L, Januario T, Kallop D, Nannini-Pepe M, Kotkow K, Marsters JC, et al. A paracrine requirement for hedgehog signalling in cancer. Nature. 2008; 455:406-410.

19. Liao X, Siu MK, Au CW, Wong ES, Chan HY, Ip PP, Ngan HY and Cheung AN. Aberrant activation of hedgehog signaling pathway in ovarian cancers: effect on prognosis, cell invasion and differentiation. Carcinogenesis. 2009; 30:131-140.

20. Steg AD, Bevis KS, Katre AA, Ziebarth A, Dobbin ZC, Alvarez RD, Zhang K, Conner M and Landen CN. Stem Cell Pathways Contribute to Clinical Chemoresistance in Ovarian Cancer. Clin Cancer Res. 2012; 18:869-881.

21. McCann CK, Growdon WB, Kulkarni-Datar K, Curley MD, Friel AM, Proctor JL, Sheikh H, Deyneko I, Ferguson JA, Vathipadiekal V, Birrer MJ, Borger DR, Mohapatra G, et al. Inhibition of Hedgehog signaling antagonizes serous ovarian cancer growth in a primary xenograft model. PloS one. 2011; 6:e28077.

22. Catenacci Dvt BN NSea. (2013). Final analysis of a Phase-
IB/randomized Phase-II study of gemcitabine (G) plus placebo $(\mathrm{P})$ or vismodegib $(\mathrm{V})$, a hedgehog $(\mathrm{Hh})$ pathway inhibitor, in patients (pts) with metastatic pancreatic cancer (PC): a University of Chicago Phase-II consortium study. ASCO.

23. Shin K, Lim A, Zhao C, Sahoo D, Pan Y, Spiekerkoetter E, Liao JC and Beachy PA. Hedgehog signaling restrains bladder cancer progression by eliciting stromal production of urothelial differentiation factors. Cancer cell. 2014; 26:521-533.

24. Bai CB, Auerbach W, Lee JS, Stephen D and Joyner AL. Gli2, but not Gli1, is required for initial Shh signaling and ectopic activation of the Shh pathway. Development. 2002; 129:4753-4761.

25. Collins MA, Bednar F, Zhang Y, Brisset JC, Galban S, Galban CJ, Rakshit S, Flannagan KS, Adsay NV and Pasca di Magliano M. Oncogenic Kras is required for both the initiation and maintenance of pancreatic cancer in mice. The Journal of clinical investigation. 2012; 122:639-653.

26. Lee J, Platt KA, Censullo P and Ruiz i Altaba A. Gli1 is a target of Sonic hedgehog that induces ventral neural tube development. Development. 1997; 124:2537-2552.

27. Chen X, Horiuchi A, Kikuchi N, Osada R, Yoshida J, Shiozawa $\mathrm{T}$ and Konishi I. Hedgehog signal pathway is activated in ovarian carcinomas, correlating with cell proliferation: it's inhibition leads to growth suppression and apoptosis. Cancer science. 2007; 98:68-76.

28. Silva IA, Bai S, McLean K, Yang K, Griffith K, Thomas D, Ginestier C, Johnston C, Kueck A, Reynolds RK, Wicha MS and Buckanovich RJ. Aldehyde dehydrogenase in combination with CD133 defines angiogenic ovarian cancer stem cells that portend poor patient survival. Cancer Res. 2011; 71:3991-4001.

29. Sofen H, Gross KG, Goldberg LH, Sharata H, Hamilton TK, Egbert B, Lyons B, Hou J and Caro I. A phase II, multicenter, open-label, 3-cohort trial evaluating the efficacy and safety of vismodegib in operable basal cell carcinoma. Journal of the American Academy of Dermatology. 2015; 73:99-105.e1. doi: 10.1016/j. jaad.2015.03.013.

30. Samkari A, White J and Packer R. SHH inhibitors for the treatment of medulloblastoma. Expert review of neurotherapeutics. 2015:1-8.

31. Geeraert P, Williams JS and Brownell I. Targeting the hedgehog pathway to treat basal cell carcinoma. Journal of drugs in dermatology. 2013; 12:519-523.

32. Hwang RF, Moore TT, Hattersley MM, Scarpitti M, Yang B, Devereaux E, Ramachandran V, Arumugam T, Ji B, Logsdon CD, Brown JL and Godin R. Inhibition of the hedgehog pathway targets the tumor-associated stroma in pancreatic cancer. Molecular cancer research. 2012; 10:1147-1157.

33. Lee JJ, Perera RM, Wang H, Wu DC, Liu XS, Han S, Fitamant J, Jones PD, Ghanta KS, Kawano S, Nagle JM, 
Deshpande V, Boucher Y, et al. Stromal response to Hedgehog signaling restrains pancreatic cancer progression. Proceedings of the National Academy of Sciences of the United States of America. 2014; 111:E3091-3100.

34. Chen M, Carkner R and Buttyan R. The hedgehog/Gli signaling paradigm in prostate cancer. Expert review of endocrinology \& metabolism. 2011; 6:453-467.

35. Levina E, Chen M, Carkner R, Shtutman M and Buttyan R. Paracrine Hedgehog increases the steroidogenic potential of prostate stromal cells in a Gli-dependent manner. The Prostate. 2012; 72:817-824.

36. Michelle L. Infinity Pharma halts pancreatic cancer trial. Boston Business J. 2012.

37. Berlin J, Bendell JC, Hart LL, Firdaus I, Gore I, Hermann RC, Mulcahy MF, Zalupski MM, Mackey HM, Yauch RL, Graham RA, Bray GL and Low JA. A randomized phase II trial of vismodegib versus placebo with FOLFOX or FOLFIRI and bevacizumab in patients with previously untreated metastatic colorectal cancer. Clin Cancer Res. 2013; 19:258-267.

38. Kaye SB, Fehrenbacher L, Holloway R, Amit A, Karlan B, Slomovitz B, Sabbatini P, Fu L, Yauch RL, Chang I and Reddy JC. A phase II, randomized, placebo-controlled study of vismodegib as maintenance therapy in patients with ovarian cancer in second or third complete remission. Clin Cancer Res. 2012; 18:6509-6518.

39. Varjosalo $M$ and Taipale J. Hedgehog: functions and mechanisms. Genes \& development. 2008; 22:2454-2472.

40. Yang L, He J, Huang S, Zhang X, Bian Y, He N, Zhang $\mathrm{H}$ and Xie J. Activation of hedgehog signaling is not a frequent event in ovarian cancers. Molecular Cancer. 2009; $8: 1-5$.

41. Bhattacharya R, Kwon J, Ali B, Wang E, Patra S, Shridhar $\mathrm{V}$ and Mukherjee P. Role of hedgehog signaling in ovarian cancer. Clin Cancer Res. 2008; 14:7659-7666.

42. Theriault BL, Shepherd TG, Mujoomdar ML and Nachtigal MW. BMP4 induces EMT and Rho GTPase activation in human ovarian cancer cells. Carcinogenesis. 2007; 28:11531162.

43. Shepherd TG, Theriault BL and Nachtigal MW. Autocrine BMP4 signalling regulates ID3 proto-oncogene expression in human ovarian cancer cells. Gene. 2008; 414:95-105.

44. Choi YJ, Ingram PN, Yang K, Coffman L, Iyengar M, Bai S, Thomas DG, Yoon E and Buckanovich RJ. Identifying an ovarian cancer cell hierarchy regulated by bone morphogenetic protein 2. Proc Natl Acad Sci U S A. 2015;112(50):E6882-8.

45. Liu S, Ginestier C, Ou SJ, Clouthier SG, Patel SH, Monville F, Korkaya H, Heath A, Dutcher J, Kleer CG, Jung Y, Dontu G, Taichman R, et al. Breast cancer stem cells are regulated by mesenchymal stem cells through cytokine networks. Cancer Res. 2011; 71:614-624.

46. So KA, Min KJ, Hong JH and Lee JK. Interleukin-6 expression by interactions between gynecologic cancer cells and human mesenchymal stem cells promotes epithelialmesenchymal transition. Int J Oncol. 2015; 47:1451-1459.

47. Castells M, Milhas D, Gandy C, Thibault B, Rafii A, Delord JP and Couderc B. Microenvironment mesenchymal cells protect ovarian cancer cell lines from apoptosis by inhibiting XIAP inactivation. Cell death \& disease. 2013; 4:e887.

48. Lis R, Touboul C, Mirshahi P, Ali F, Mathew S, Nolan DJ, Maleki M, Abdalla SA, Raynaud CM, Querleu D, AlAzwani E, Malek J, Mirshahi M, et al. Tumor associated mesenchymal stem cells protects ovarian cancer cells from hyperthermia through CXCL12. Int J Cancer. 2011; 128:715-725.

49. Touboul C, Lis R, Al Farsi H, Raynaud CM, Warfa M, Althawadi H, Mery E, Mirshahi M and Rafii A. Mesenchymal stem cells enhance ovarian cancer cell infiltration through IL6 secretion in an amniochorionic membrane based 3D model. J Transl Med. 2013; 11:28.

50. Yang Y, Bucan V, Baehre H, von der Ohe J, Otte A and Hass R. Acquisition of new tumor cell properties by MSCderived exosomes. Int J Oncol. 2015; 47:244-252.

51. Yang Y, Otte A and Hass R. Human mesenchymal stroma/stem cells exchange membrane proteins and alter functionality during interaction with different tumor cell lines. Stem Cells Dev. 2015; 24:1205-1222.

52. Spaeth EL, Dembinski JL, Sasser AK, Watson K, Klopp A, Hall B, Andreeff M and Marini F. Mesenchymal stem cell transition to tumor-associated fibroblasts contributes to fibrovascular network expansion and tumor progression. PLoS One. 2009; 4:e4992.

53. Stagg J and Galipeau J. Mechanisms of immune modulation by mesenchymal stromal cells and clinical translation. Curr Mol Med. 2013; 13:856-867.

54. Coffman L, Mooney C, Lim J, Bai S, Silva I, Gong Y, Yang $\mathrm{K}$ and Buckanovich RJ. Endothelin receptor-A is required for the recruitment of antitumor $\mathrm{T}$ cells and modulates chemotherapy induction of cancer stem cells. Cancer biology \& therapy. 2013; 14:184-192.

55. Schneider CA, Rasband WS and Eliceiri KW. NIH Image to ImageJ: 25 years of image analysis. Nature methods. 2012; 9:671-675.

56. Lim JJ, Yang K, Taylor-Harding B, Wiedemeyer WR and Buckanovich RJ. VEGFR3 inhibition chemosensitizes ovarian cancer stemlike cells through down-regulation of BRCA1 and BRCA2. Neoplasia. 2014; 16:343-353 e341342.

57. Lee MJ, Hatton BA, Villavicencio EH, Khanna PC, Friedman SD, Ditzler S, Pullar B, Robison K, White KF, Tunkey C, LeBlanc M, Randolph-Habecker J, Knoblaugh SE, et al. Hedgehog pathway inhibitor saridegib (IPI-926) increases lifespan in a mouse medulloblastoma model. Proceedings of the National Academy of Sciences of the United States of America. 2012; 109:7859-7864.

58. Pulaski HL, Spahlinger G, Silva IA, McLean K, Kueck 
AS, Reynolds RK, Coukos G, Conejo-Garcia JR and Buckanovich RJ. Identifying alemtuzumab as an antimyeloid cell antiangiogenic therapy for the treatment of ovarian cancer. Journal of translational medicine. 2009; $7: 49$. 